\title{
Quality characteristics, chemical composition, and sensory properties of butter from cows on pasture versus indoor feeding systems
}

\author{
Tom F. O’Callaghan, ${ }^{*} \ddagger$ Hope Faulkner, $\ddagger$ Stephen McAuliffe,§\# Maurice G. O’Sullivan,II Deirdre Hennessy, \\ Pat Dillon, $\rceil$ Kieran N. Kilcawley, $\ddagger$ Catherine Stanton, ${ }^{*} \ddagger$ and R. Paul Ross ${ }^{*} \ddagger \prod^{1}$ \\ ${ }^{*}$ APC Microbiome Institute, University College Cork, Cork, Ireland \\ †Department of Microbiology, University College Cork, Cork, Ireland \\ ‡Department of Food Biosciences, Teagasc Food Research Centre, Moorepark, Fermoy, Cork, Ireland \\ $\S$ Teagasc Animal and Grassland Research and Innovation Centre, Moorepark, Fermoy, Cork, Ireland \\ \#School of Biological Sciences, Queen's University, Belfast BT7 1NN, United Kingdom \\ $\|$ School of Food and Nutritional Sciences, University College Cork, Cork, Ireland \\ TCollege of Science Engineering and Food Science, University College Cork, Cork, Ireland
}

\begin{abstract}
This study evaluated the effects of 3 widely practiced cow feeding systems in the United States, Europe, and Southern Hemisphere regions on the characteristics, quality, and consumer perception of sweet cream butter. Fifty-four multiparous and primiparous Friesian cows were divided into 3 groups $(\mathrm{n}=18)$ for an entire lactation. Group 1 was housed indoors and fed a total mixed ration diet (TMR) of grass silage, maize silage, and concentrates; group 2 was maintained outdoors on perennial ryegrass-only pasture (GRS); and group 3 was maintained outdoors on a perennial ryegrass/ white clover pasture (CLV). Mid-lactation butter was manufactured in triplicate with milk from each group in June 2015 (137 $\pm 7 \mathrm{~d}$ in milk) and was analyzed over a 6-mo storage period at $5{ }^{\circ} \mathrm{C}$ for textural and thermal properties, fatty acid composition, sensory properties, and volatile compounds. The nutritional value of butters was improved by pasture feeding, and butter from pasture-fed cows had significantly lower thrombogenicity index scores compared with butters from TMR-fed cows. In line with these results, pasture-derived milks (GRS and CLV) produced butter with significantly higher concentrations of conjugated linoleic acid (cis9,trans-11) and trans- $\beta$-carotene than TMR butter. Alterations in the fatty acid composition of butter contributed to significant differences in textural and thermal properties of the butters. Total mixed ration-derived butters had significantly higher hardness scores at room temperature than those of GRS and CLV. Onset of crystallization for TMR butters also occurred at significantly higher temperatures compared
\end{abstract}

Received April 4, 2016.

Accepted September 2, 2016.

${ }^{1}$ Corresponding author: p.ross@ucc.ie with pasture butters. Volatile analysis of butter by gas chromatography-mass spectrometry identified 25 compounds present in each of the butters, 5 of which differed significantly based on feeding system, including acetone, 2-butanone, 1-pentenol, toluene, and $\beta$-pinene. Toluene was very significantly correlated with pasturederived butter. Sensory analysis revealed significantly higher scores for GRS-derived butter in several attributes including "liking" of appearance, flavor, and color over those of TMR butter. Partial least square regression plots of fatty acid profiles showed clear separation of butter derived from grazed pasture-based perennial ryegrass or perennial rye/white clover diets from that of a TMR system, offering further insight into the ability of fatty acid profiling to verify such pasture-derived dairy products.

Key words: pasture, total mixed ration, cow, diet, butter, fatty acid

\section{INTRODUCTION}

The consumption of milk fat has, in the past, been a concern for consumers compared with spread and margarine alternatives because of its high levels of SFA, whose intake has been linked to high cholesterol, atherosclerosis, and heart disease (Ulbricht and Southgate, 1991; Rasmussen et al., 2006). However, recent reviews and meta-analysis of the topic have concluded that milk intake has at least a neutral effect on multiple health outcomes, and cows' milk consumption may actually be beneficial in combatting osteoporosis, cardiovascular disease, stroke, type 2 diabetes, and some cancers (Armas et al., 2016; Lamarche et al., 2016).

The different farming and feeding systems of dairy cows practiced throughout the world are dictated by several factors, including land availability, climate, and dairy cow requirements. The feeding system of dairy 
cows is widely understood to be able to directly affect the composition of milk, particularly the fatty acid (FA) composition of milk fat (Chilliard et al., 2007). The resulting milk FA profile can in turn have profound effects on the sensory, textural, nutritional, and shelf-life properties of dairy fat products such as butter (Couvreur et al., 2006; Hurtaud and Peyraud, 2007). Indeed, the level of SFA and UFA in milk fat is closely dependent on the nature of the cows' diet (Chilliard et al., 2001). Fresh grass feeding systems, which are widely practiced in Ireland and New Zealand, produce a milk fat with higher proportions of UFA compared with those derived from TMR systems (Couvreur et al., 2006) widely practiced in the United States, Asia, and parts of Europe. Previous studies have shown that the texture and hardness of butter are related to the levels of SFA and UFA because the lower melting point of UFA produces a less firm and more spreadable butter (Hurtaud et al., 2007). Feeding system can also have an effect on the natural color of products, and maize silage and TMR diets have been shown to produce dairy products that are much whiter in color than those of pasture feeding systems, which have a characteristic yellow color (Hurtaud et al., 2002). With this in mind, a consumer perception of the spreadability of butters being associated with their color has been reported (Rohm et al., 1997).

Consumer acceptance of butter is influenced by its sensory properties, which are dependent on several factors including flavor, aroma, textural, appearance, and rheological factors. The volatile composition of butter has been well studied, with over 287 volatile compounds being identified (Peterson and Reineccius, 2003). Feeding regimen has been shown to have an effect on the sensory and volatile properties of cows' milk, with milk from TMR systems reportedly having flavor profiles that are considerably different from pasture-derived milk (Bendall, 2001).

The benefits of including white clover in pasture swards has been documented and is associated with increased milk production (Egan et al., 2015); however, limited information is available on the effects of inclusion of white clover with perennial rye pastures on the characteristics and sensory properties of dairy products. At present, a consumer perception exists that dairy products from cows that are maintained outdoors and consume fresh grass are "more natural" than those from TMR farming systems (Verkerk, 2003). This perception has become a major marketing scheme for countries such as Ireland and New Zealand, which practice fresh grass feeding, for promotion of dairy products. However, little information is currently available to substantiate this notion or to verify dairy products derived from fresh grass feeding systems. Although many studies have been conducted in this area in the past, those have generally been from noncontinuous cross-over designs. Limited information is available from studies using a larger herd size and cows that have been maintained on their respective diets throughout an entire lactation in a commercial farm setting or from studies using larger bulk milk volumes, which would provide a better reflection of milks being provided to the dairy manufacturer.

The objectives of this study were to investigate (1) the effect of 3 widely practiced feeding systems: a TMR diet indoors, perennial ryegrass (Lolium perenne L.) outdoors, and perennial ryegrass/white clover (Trifolium repens $\mathrm{L}$.) outdoors, on the chemical composition, sensory properties, and quality of mid-lactation sweet cream butter, and (2) the potential attributes that may be used to differentiate such pasture-derived dairy products from those of a TMR system.

\section{MATERIALS AND METHODS}

\section{Reagents}

Hexane, heptane, formic acid, $25 \%$ sodium methoxide, valeric acid (C5:0), undecylic acid (C11:0), and margaric acid (C17:0) were purchased from Sigma Aldrich (Dublin, Ireland). Diethyl ether was purchased from Fisher Scientific (Dublin, Ireland). Certified free fatty acid (FFA) standard mix containing C4:0 to C22:0 free acids (GLC Reference standard 74 "Free acid"), trinonadecanoin (C19:0) (part number: T-165), and a standard mix of CLA C18:2 cis-9,trans-11 and C18:2 cis-12,trans-10 (part number: UC-59M) were purchased from Nu-Chek Prep Inc. (Waterville, MN). Fatty acid methyl ester standard mix containing C4:0 to C24:0 methyl esters (part no: 18919-1AMP) was purchased from Sigma Aldrich. Aminopropyl cartridges (500 mg, part no. 12102041) were obtained from Agilent Technologies (Little Island, Cork, Ireland).

\section{Experimental Design}

Fifty-four spring-calving Friesian cows were allocated to 3 groups $(\mathrm{n}=18)$ at the Teagasc Animal and Grassland Research and Innovation Centre, Moorepark, Fermoy, Co. Cork, Ireland. Groups were randomized based on milk yield, milk solids yield, calving date (mean calving date February 19, 2015) and lactation number. Group 1 was housed indoors and fed a TMR diet; group 2 was maintained outdoors on perennial ryegrass only pasture (GRS); and group 3 was maintained outdoors on a perennial ryegrass/white clover pasture (CLV). For further information on the chemical and 
nutritional values of each of the diets, see O'Callaghan et al. (2016) and Supplemental Tables S1, S2, and S3 (http://dx.doi.org/10.3168/jds.2016-11271). Briefly, the TMR diet consisted of $7.15 \mathrm{~kg}$ of grass silage, 7.15 $\mathrm{kg}$ of maize silage, and $8.3 \mathrm{~kg}$ of concentrates on a DM basis. Cows within the TMR system were fed at 0830 h daily, using electronically controlled Griffith Elder Mealmaster individual feed bins (Griffith Elder and Company Ltd., Suffolk, UK), and feed was available ad libitum. Pasture-based cows consumed $\sim 18 \mathrm{~kg}$ of DM/d measured by pre- and postgrazing sward heights daily using the rising plate meter (Jenquip, Feilding, New Zealand), while pregrazing herbage mass was measured with an Etesia mower (Etesia UK Ltd., Warwick, UK). The CLV sward contained $20 \%$ clover and was measured according to Egan et al. (2013). Milking took place at 0730 and $1530 \mathrm{~h}$ daily. To obtain a representative sample of milk, the cows in each of the 3 feeding systems were milked separately into designated 5,000-L refrigerated tanks. The evening milk was stored at $4^{\circ} \mathrm{C}$ overnight, to which the morning milk was then added, tanks were maintained at $4^{\circ} \mathrm{C}$ and agitated before sample collection. Milk was collected from each of the groups in the trial for butter manufacture on 3 separate occasions over a 3 -wk period in mid-June 2015, when cows were $137 \pm 7 \mathrm{~d}$ in milk, batches of butter were produced $7 \mathrm{~d}$ apart, and each of the butters within each batch were manufactured on the same day.

\section{Sample Collection and Butter Manufacture}

Butter-making trials were performed in Moorepark Technology Ltd. (MTL, Moorepark, Fermoy, Co. Cork, Ireland) with milk from each of the 3 groups in the study. For each batch, 400 to $450 \mathrm{~L}$ of milk from each group was pasteurized using a Unison pasteurizer (Unison Engineering Ltd., Limerick, Ireland) at $72^{\circ} \mathrm{C}$ for $15 \mathrm{~s}$, skimmed at $50^{\circ} \mathrm{C}$ using a cream separator (Westfalia separator d-4740, GEA, Naas, Ireland), and standardized to produce a cream containing 38 to $40 \%$ fat content. Pearson's square was used to assess the amount of skim milk required to obtain a desired cream fat content. Cream was then stored for $72 \mathrm{~h}$ at $5^{\circ} \mathrm{C}$ in sealed containers to facilitate crystallization of milk fat.

The evening before cream processing, the butter churn was washed with hot water and stored in a Super-Sil detergent solution (Biocel Ltd., Little Island, Cork, Ireland) overnight and rinsed with chilled reverse osmosis-treated water before cream processing.

For butter manufacture, 4.5 to $5.0 \mathrm{~kg}$ of cream was churned at $7^{\circ} \mathrm{C}$ in a $19^{\circ} \mathrm{C}$ room using a "Milky" Butter churn model FJ-10 (Sebright Supplies Limited, Olney, UK). Cream was churned at $150 \mathrm{rpm}$ until the "break" was observed and butter grains were formed. Buttermilk was separated from the butter grains, and butter was washed 3 times with cold reverse osmosis-treated water $\left(\sim 10^{\circ} \mathrm{C}\right)$ in the churn until drained water was clear and free from traces of buttermilk. Washed butter was then weighed, and $2 \%$ salt was added in 40 to $50 \%$ salt slurry. The salt slurry was poured over the washed butter and mixed in by kneading the butter at $60 \mathrm{rpm}$. The butter was then worked at $30 \mathrm{rpm}$ for several minutes to reduce free water content. Butter was packaged by hand using a spatula into $100-\mathrm{mL}$ containers (Sarstedt, Drinagh, Co. Wexford, Ireland).

Pots of butter were then stored at $5^{\circ} \mathrm{C}$ over a 6 -mo period. During this period, the butter was analyzed for chemical composition, thermal and textural properties, FA composition, and sensory properties and analysis of volatile compounds was done by GC-MS.

All analyses of butters from individual batches unless otherwise stated were analyzed in duplicate and results reported are the mean and standard deviation (SD) of results.

\section{Chemical Analysis}

Total solids content of butter samples was measured by recording the weight lost from samples (initial weight of $10 \pm 0.5 \mathrm{~g}$ ) after drying in an oven at $102^{\circ} \mathrm{C}$ for at least $15 \mathrm{~h}$. Fat content of cream and butter samples was analyzed by the Röse-Gottlieb method (International Dairy Federation, 1996).

\section{Butter Hardness}

Hardness of butter from each of the feeding systems was analyzed using a TA-HDi texture analyzer (Stable Micro Systems Ltd., Surrey, UK) equipped with a 100$\mathrm{kg}$ load cell and a $30^{\circ}$ conical probe in a room maintained at $20^{\circ} \mathrm{C}$. Triplicate butter sample molds were prepared for hardness analysis at both $5^{\circ} \mathrm{C}$ and $20^{\circ} \mathrm{C}$, using a cylindrical aluminum press with a $3-\mathrm{cm}$ diameter and 3-cm height; samples were removed from the mold and wrapped in aluminum foil and placed in a $5^{\circ} \mathrm{C}$ storage room before analysis. An extra sample was prepared and used as a temperature reference block with a digital thermometer inserted into its center. Analysis was performed by lowering a $30^{\circ}$ conical probe perpendicularly at $1 \mathrm{~mm} / \mathrm{s}$ to a depth of $12 \mathrm{~mm}$ from the surface of the sample, as described by Bobe et al. (2003). One measurement per sample was performed. Hardness values for each sample were determined as the highest peak force recorded during each analysis.

Samples for analysis at $20^{\circ} \mathrm{C}$ were placed in a temperature-controlled room and left to acclimate $(\sim 2 \mathrm{~h})$ as 
indicated by the reference butter. Samples for analysis at $5^{\circ} \mathrm{C}$ were removed from refrigerated storage immediately before analysis. For each butter at any given sampling time, samples were analyzed at both $5^{\circ} \mathrm{C}$ and $20^{\circ} \mathrm{C}$, and the temperature of each butter sample was also measured immediately post analysis. Texture analysis was performed on butter after 1,3 , and 6 mo of storage.

\section{Color}

Color measurements were taken from the surface of newly opened cups of butter following $1 \mathrm{wk}, 1 \mathrm{mo}, 3$ mo, and $6 \mathrm{mo}$ of storage at $5^{\circ} \mathrm{C}$. Five replications of $\mathrm{L}^{*}$ (lightness), a* (red-green color), and b*(yellow-blue color) values were taken at random locations across the surface of the butters using a Minolta Chroma-Meter CR-400 (Mason Technology Ltd., Dublin, Ireland). The $\mathrm{L}^{*}$ value defines the position of the sample on the lightness-darkness axis, $a^{*}$ on the green-red axis, and $b^{*}$ on the blue-yellow axis as described by the Lighting International Commission (Commission Internationale de l'Éclairage, 1996). The mean of 5 replications was calculated and used as a unit for 1 replicate butter trial in statistical analysis.

\section{$\beta$-Carotene Analysis}

Butter samples were analyzed in triplicate for trans$\beta$-carotene content by Eurofins Food Testing Ireland Ltd. (Dublin, Ireland). The trans- $\beta$-carotene was saponified using ethanolic potassium hydroxide solution for $16 \mathrm{~h}$ at room temperature and extracted once with ethanol:hexane (4:3 vol/vol) and 2 times with hexane. The trans- $\beta$-carotene analysis was performed by reverse-phase HPLC with a UV diode array detector at $452 \mathrm{~nm}$. For quantification, a 3-point calibration curve was used. The calibration standards used were pure compounds from Sigma Aldrich, purity $>98 \%$. The purity of the standard for each calibration was determined by a series of spectrophotometric measurements (UV $340,455,483 \mathrm{~nm})$.

\section{Thermal Analysis}

Thermal properties of butters produced from each feeding system were examined by differential scanning calorimetry using a TA Q2000 calorimeter (Waters Chromatography, Dublin, Ireland). Thirty milligrams of butter melted at $40^{\circ} \mathrm{C}$ was weighed into a hermetic Tzero aluminum pan (Waters Chromatography) and press sealed. An empty hermetic pan was used as reference. For analysis, samples were equilibrated to $25^{\circ} \mathrm{C}$ for $1 \mathrm{~min}$, heated at $20^{\circ} \mathrm{C} / \mathrm{min}$ to $60^{\circ} \mathrm{C}$, and held for 5 min to completely melt the fat and eliminate all crystal nuclei. They were then cooled at $5^{\circ} \mathrm{C} / \mathrm{min}$ from 60 to $-10^{\circ} \mathrm{C}$ and then heated at $2^{\circ} \mathrm{C} / \mathrm{min}$ to a final temperature of $60^{\circ} \mathrm{C}$. Data from thermal analysis were analyzed using TA Universal Analysis 2000 program v4.5A (TA Instruments- Waters LLC). Cooling profiles were analyzed for temperature at beginning of fat crystallization (T-onset) and each crystallization peak. Final melting temperatures (T-offset) were recorded from each sample heating profile as outlined by Couvreur et al. (2006). Each sample was analyzed in duplicate, and results shown are the mean and SD of each set of analysis.

\section{Fatty Acid Analysis}

Lipid Extraction. Lipid extraction was performed according to the procedure outlined by De Jong and Badings (1990) with modifications. Briefly, $5 \mathrm{~g}$ of butter was added to $10 \mathrm{~mL}$ of ethanol (98\% purity), and 1 $\mathrm{mL}$ of $2.5 \mathrm{M} \mathrm{H}_{2} \mathrm{SO}_{4}$, and $1 \mathrm{~mL}$ of internal free acid standard (C5:0, C11:0, and C17:0 at 1,000 ppm in heptane) were added to each sample mixture. This mixture was extracted 3 times with $15 \mathrm{~mL}$ of diethyl ether/heptane $(1: 1 \mathrm{vol} / \mathrm{vol})$, and each time the solution was clarified by centrifugation at $1,500 \times g$ for $5 \mathrm{~min}$. The collected extracts were pooled for solid-phase extraction.

Solid-Phase Extraction. The 500-mg aminopropyl columns (Agilent Technologies Ltd.) were preconditioned with $10 \mathrm{~mL}$ of heptane. The lipid extract was applied to the column, a vacuum was applied, and the triglycerides were eluted. Residual triglycerides were removed using $10 \mathrm{~mL}$ of $20 \%$ diethyl ether/hexane (vol/ $\mathrm{vol}$ ), and the entire triglyceride extract was stored at $-20^{\circ} \mathrm{C}$. The FFA were eluted using $5 \mathrm{~mL}$ of $2 \%$ formic acid/diethyl ether (vol/vol) in glass test tubes. At no point were the columns left to dry. The entire FFA extract was immediately separated and stored in 2-mL amber vials (part no: 5182-0716, Agilent Technologies Ltd.), which were capped with polytetrafluoroethylene (PTFE)/white silicone septa (part no: 5185-5864, Agilent Technologies Ltd.). For FFA analysis, $0.5 \mu \mathrm{L}$ of this solution was directly injected (on-column injection) on the GC. For FAME analysis, samples of extracted triglyceride fractions were dried down under nitrogen and $60 \mathrm{mg}$ of extracted fat was methylated.

Methyl Ester Derivatization of Triglycerides. Triglycerides were derived by adding $4.8 \mathrm{~mL}$ of C19:0 triacylglycerol $(500 \mathrm{mg} / \mathrm{L})$ in heptane to $\sim 60 \mathrm{mg}$ of extracted fat sample. Two hundred microliters of $2 M$ sodium methoxide solution was then added, and the sample was mixed vigorously for about 30 s. Subsequently, $1 \mathrm{~g}$ of sodium hydrogen sulfate monohydrate 
(Sigma Aldrich) was added to the solution and shaken vigorously. After the salt had settled, the upper layer containing the FAME was decanted into a clean test tube and diluted with $8 \mathrm{~mL}$ of heptane. Methylated FAME were stored at $-20^{\circ} \mathrm{C}$ in $2-\mathrm{mL}$ amber vials capped with PTFE/white silicone septa until analysis.

Instrumentation. Analysis of FFA was performed on a Varian CP3800 gas chromatograph (Aquilant, Dublin, Ireland) equipped with a CP8400 autosampler and flame ionization detector and a 1079 universal capillary injector. The column was a Zebron ZB-FFAP capillary column $(30 \mathrm{~m} \times 0.32 \mu \mathrm{m}$ i.d., $0.25-\mu \mathrm{m}$ phase thickness; part no. 7HM-G009-11, Phenomenex Inc., Cheshire, UK). Total FA triglyceride analysis (FAME) was carried out on an Agilent 7890B gas chromatograph (equipped with a GC80 autosampler) and flame ionization detector and a multimode inlet injector (Agilent Technologies Ltd.). The column was a Select FAME capillary column $(100 \mathrm{~m} \times 250 \mu \mathrm{m}$ i.d., $0.25-\mu \mathrm{m}$ phase thickness; product no. CP7420, Agilent Technologies Ltd.).

Solid-phase microextraction (SPME) was performed using Vac Elut 20 Manifold and adaptor caps (parts no. 12234104 and 12131001) from Agilent Technologies Ltd. and a KNF vacuum pump (Scientific \& Chemical Supplies Ltd., Carrigtwohill, Co. Cork, Ireland).

Standard curves for both FFA and FAME analysis, along with in-run quality control samples, were prepared using Agilent 7696A Sample Prep Workbench (Agilent Technologies Ltd.).

Instrument Conditions for Analysis of FFA. The injector was maintained at $25^{\circ} \mathrm{C}$ for $1 \mathrm{~min}$; the temperature was raised to $240^{\circ} \mathrm{C}$ at $30^{\circ} \mathrm{C} / \mathrm{min}$. The injector and autosampler were operated in on-column mode using an injection volume of $0.5 \mu \mathrm{L}$. The column oven was held at $40^{\circ} \mathrm{C}$ for $2 \mathrm{~min}$ and raised to $240^{\circ} \mathrm{C}$ at $7.5^{\circ} \mathrm{C} / \mathrm{min}$; this temperature was held for $23.33 \mathrm{~min}$. The total run time was $52 \mathrm{~min}$. The flame ionization detector was operated at $300^{\circ} \mathrm{C}$. The carrier gas was helium and was held at a constant flow of $1.2 \mathrm{~mL} / \mathrm{min}$.

Instrument Conditions for Analysis of FAME. The injector was held at $250^{\circ} \mathrm{C}$ for the entire run and was operated in split mode using a ratio of 1:10 and an injection volume of $1 \mu \mathrm{L}$. The inlet liner was a split gooseneck liner (part no. 8004-0164, Agilent Technologies Ltd.). The column oven was held at $80^{\circ} \mathrm{C}$ for 8 min, raised to $200^{\circ} \mathrm{C}$ at $8.5^{\circ} \mathrm{C} / \mathrm{min}$, and held at that temperature for $55 \mathrm{~min}$. The total run time was 77.12 min. The flame ionization detector was operated at $300^{\circ} \mathrm{C}$. The carrier gas was helium and was held at a constant flow of $1.0 \mathrm{~mL} / \mathrm{min}$. Results were processed using OpenLab CDS Chemstation edition software version Rev.C.01.05 (Agilent Technologies Ltd.)

\section{Analysis of Volatile Compounds by GC-MS}

For analysis of volatile compounds in butter samples, $2 \mathrm{~g}$ of the butter was placed in a $20-\mathrm{mL}$ screw-capped headspace vial with a silicone/PTFE liner (Apex Scientific Ltd., Maynooth, Co. Kildare, Ireland) and equilibrated to $40^{\circ} \mathrm{C}$ for $10 \mathrm{~min}$ with pulsed agitation of $5 \mathrm{~s}$ at $500 \mathrm{rpm}$. The samples were analyzed in triplicate using a Shimadzu AOC-5000 Plus injection system (Shimadzu UK Ltd., Milton Keynes, UK). A single $75-\mu \mathrm{m}$ divinylbenzene/carboxen/polydimethylsiloxane fiber was used for analysis. The SPME fiber was exposed to the headspace above the samples for $20 \mathrm{~min}$ at a depth of $1.2 \mathrm{~cm}$. The fiber was retracted and injected into the GC inlet and desorbed for $2 \mathrm{~min}$ at $250^{\circ} \mathrm{C}$. Injections were made on a Shimadzu 2010 plus GC with an Agilent DB-5 $(60 \mathrm{~m} \times 0.25 \mathrm{~mm} \times$ $0.25 \mu \mathrm{m}$ ) column using a multipurpose injector with a merlin microseal. The temperature of the column oven was set at $35^{\circ} \mathrm{C}$, then increased at $6.5^{\circ} \mathrm{C} / \mathrm{min}$ to $230^{\circ} \mathrm{C}$, and further increased at $15^{\circ} \mathrm{C} / \mathrm{min}$ to $320^{\circ} \mathrm{C}$, yielding a total GC run time of $41.5 \mathrm{~min}$. The carrier was helium at a constant pressure of 23 psi. The detector was a Shimadzu TQ8030 MSD triple quadrupole mass spectrometer (Shimadzu UK Ltd.) and was used in single quadrupole mode. The ion source temperature was $220^{\circ} \mathrm{C}$, the interface temperature was set at $280^{\circ} \mathrm{C}$, and the MS mode was electronic ionization $(-70 \mathrm{v})$, with the mass range scanned between 35 and $250 \mathrm{amu}$. Data files were processed using Targetview software (version 4.0.0.18, Markes International, Llantrisant, UK) compounds were identified based on spectra matched against those in the NIST 2011 database, and an internal library was created with Targetview based on linear retention indices, using the van Den Dool and Kratz procedure (van Den Dool and Kratz, 1963). An autotune of the GCMS was performed before the analysis to ensure optimal GC-MS performance. A set of external standards was also analyzed at the start and end of the sample set and abundances were compared with known amounts to ensure that both the SPME extraction and MS detection was performing within specification.

\section{Hedonic Sensory Analysis and Ranking Descriptive Analysis of Butters}

Butter samples for sensory analysis were aged at $5^{\circ} \mathrm{C}$ for $48 \mathrm{~h}$ and then stored frozen at $-80^{\circ} \mathrm{C}$ before analysis. Twenty-six naïve assessors aged between 23 and 50 years old were recruited at University College Cork, Ireland. Inclusion criteria for assessors were availability, good health, and motivation to participate on all days of the experiment and that they were butter consum- 
ers. Sensory acceptance testing was conducted using these untrained assessors (Stone and Sidel, 2004; Stone et al., 2012b). The experiment was conducted in panel booths, in a fluorescent-lighted room that conformed to international standards (International Organization for Standardization, 1988). Assessors used the sensory hedonic descriptors provided to them for 3 different butter samples (TMR, GRS, and CLV) (see Supplemental Table S4, http://dx.doi.org/10.3168/jds.2016-11271) presented in duplicate and from 2 separate production batches. Samples were held at refrigeration temperatures overnight $\left(5^{\circ} \mathrm{C}\right)$ before monadic presentation at ambient temperatures $\left(\sim 21^{\circ} \mathrm{C}\right)$ to the naïve assessor panel; samples were coded with a randomly selected 3 -digit code. The butter was immediately served to assessors. Assessors were provided with deionized water and instructed to cleanse their palates between tastings. Additionally, each assessor was asked to indicate their degree of liking on a 10-cm line scale ranging from 0 (extremely dislike) at the left to 10 (extremely like) at the right. The rating was subsequently scored in centimeters from the left. The order of the presentation of all test samples was randomized to prevent first-order and carryover effects, and all samples were presented in duplicate. The assessors then participated in ranking descriptive analysis (Cavanagh et al., 2014; Yarlagadda et al., 2014; Fellendorf et al., 2016) using the consensus list of sensory descriptors provided to them, which was also measured on a $10-\mathrm{cm}$ line scale. All samples were again presented in duplicate (Stone et al., 2012a).

\section{Nutritional Indices and FA Ratios}

Several FA ratios and nutritional indices of milks from each of the feeding systems are reported. The summation of n-6 (linolelaidic acid, linoleic acid, eicosatrienoic acid, and arachidonic acid), n-3 ( $\alpha$-linolenic acid), and n-9 (oleic acid and erucic acid) FA are reported. Other longer chain n-3 fatty acids, including eicosapentaenoic acid and docosahexaenoic acid, have been found in milk at low concentrations, but were not detected in our analysis. Similar to Benbrook et al. (2013), to more fully reflect variations in levels of health promoting dairy FA, we also included total n-3 and CLA. As Benbrook et al. (2013) described, we included the ratio of n- 6 fatty acids to n-3 + total CLA to fully reflect these variations. The atherogenicity index and thrombogenicity index outlined by Ulbricht and Southgate (1991) are dietary risk indices for cardiovascular disease. The atherogenicity index indicates the relationship between fatty acids with pro-atherogenic properties and those with anti-atherogenic properties, reflecting the inhibition of plaque aggregation and the levels of esterified FA, cholesterol, and phospholipids. The thrombogenic- ity index shows the relationship between prothrombogenic (saturated) and antithrombogenic FA, indicating the tendency for clots to form in the blood (Šimat et al., 2015).

The atherogenicity index (AI) and thrombogenicity index (TI) were calculated as described by Ulbricht and Southgate (1991):

$$
\mathrm{AI}=\frac{\mathrm{C} 12: 0+(4 \times \mathrm{C} 14: 0)+\mathrm{C} 16: 0}{\mathrm{n}-6 \mathrm{PUFA}+\mathrm{n}-3 \text { PUFA }+ \text { MUFA }},
$$

$\mathrm{TI}=$

$$
\frac{\mathrm{C} 14: 0+\mathrm{C} 16: 0+\mathrm{C} 18: 0}{(0.5 \times \text { MUFA })+(0.5 \times \mathrm{n}-6 \text { PUFA })+(3 \times \mathrm{n}-3 \text { PUFA })+\left(\frac{\mathrm{n}-3 \text { PUFA }}{\mathrm{n}-6 \text { PUFA }}\right)} \text {. }
$$

\section{Statistical Analysis}

Statistical analysis was performed using SPSS v18.0 (IBM Statistics Inc., Armonk, NY). Data sets were analyzed for normality using the Shapiro-Wilk's test and for homogeneity of variance using the Levene's test.

Analyses that were carried out at only one time point and were normally distributed were analyzed using oneway ANOVA ( $\beta$-carotene, FAME, FFA, thermal properties, sensory analysis) with post hoc Tukey test. For data that appeared to have nonnormal distribution, a Kruskal-Wallis test was performed (volatile analysis). If the Kruskal-Wallis test result was significant, post hoc Mann-Whitney test was used to analyze for differences between individual groups, and significant results were adjusted using the Bonferroni correction.

For data sets from analyses that were carried out at several time points throughout the study (color analysis and texture analysis), a between- and within-subjects repeated measures ANOVA with post hoc Tukey test was used to compare butters from herds on different feeding systems (TMR, GRS, and CLV) throughout the storage period (6 mo).

Multivariate data analysis (partial least squares regression, PLSR) was applied to investigate relationships between FAME, sensory analysis, and volatiles analysis data and the experimental treatments (different feeding regimens) using The Unscrambler $\mathrm{X}$ multivariate analysis program, v10.3 (CAMO ASA, Trondheim, Norway). $P$-values $\leq 0.05$ were considered significant, and results of statistical tests with $P$-values of 0.000 are represented as $P<0.001$.

\section{RESULTS}

Raw milks from each of the feeding systems were separated to produce creams with similar $(P>0.05)$ 
fat contents (mean \pm SD) of $40.29 \pm 2.35 \%$ for TMR, $40.64 \pm 1.08 \%$ for GRS, and $43.29 \pm 2.32 \%$ for CLV. Churning times varied between creams: $45.9 \pm 8.9$ min for TMR, $40.9 \pm 0.5 \mathrm{~min}$ for GRS, and $41.2 \pm 4.9 \mathrm{~min}$ for CLV. Butters from each of the feeding systems had a mean fat and moisture content, respectively, of 83.60 $\pm 0.67 \%$ and $13.92 \pm 0.53 \%$ for TMR, $83.27 \pm 0.80 \%$ and $14.19 \pm 1.12 \%$ for GRS, and $83.00 \pm 1.06 \%$ and $13.08 \pm 1.8 \%$ for CLV, which were not significantly different.

\section{Fatty Acid Composition}

A total of $27 \mathrm{FA}$ were quantified (g/100 $\mathrm{g}$ of butter fat) from each butter sample. Overall, 12 of these FA varied significantly $(P \leq 0.05)$ between feeding systems. A full list of butter FA contents (mean \pm SD) is displayed in Table 1.

Among SFA, significant differences between butters were recorded for pentadecanoic acid (C15:0), palmitic acid (C16:0), behenic acid (C22:0) and tricosanoic acid

Table 1. Relationship between cow feeding system and the fatty acid triglyceride content of butter ${ }^{1}$

\begin{tabular}{|c|c|c|c|c|}
\hline \multirow[b]{2}{*}{ Fatty acid } & \multicolumn{3}{|c|}{ Feeding system ${ }^{2}$} & \multirow[b]{2}{*}{$P$-value } \\
\hline & TMR & GRS & CLV & \\
\hline Butyric acid (C4:0) & $3.81 \pm 0.35$ & $3.54 \pm 0.29$ & $3.33 \pm 0.28$ & 0.070 \\
\hline Caproic acid (C6:0) & $1.98 \pm 0.19$ & $1.86 \pm 0.18$ & $1.72 \pm 0.12$ & 0.073 \\
\hline Caprylic acid (C8:0) & $1.06 \pm 0.10$ & $1.04 \pm 0.13$ & $0.97 \pm 0.07$ & 0.371 \\
\hline Capric acid (C10:0) & $2.30 \pm 0.23$ & $2.37 \pm 0.35$ & $2.20 \pm 0.19$ & 0.625 \\
\hline Undecanoic acid (C11:0) & $0.04 \pm 0.01$ & $0.05 \pm 0.01$ & $0.04 \pm 0.00$ & 0.442 \\
\hline Lauric acid (C12:0) & $2.59 \pm 0.27$ & $2.74 \pm 0.47$ & $2.52 \pm 0.25$ & 0.615 \\
\hline Tridecanoic acid (C13:0) & $0.07 \pm 0.01$ & $0.08 \pm 0.02$ & $0.06 \pm 0.01$ & 0.069 \\
\hline Myristic acid (C14:0) & $8.36 \pm 0.83$ & $8.36 \pm 0.89$ & $7.74 \pm 0.56$ & 0.375 \\
\hline Myristoleic acid (C14:1) & $0.73 \pm 0.09$ & $0.82 \pm 0.14$ & $0.70 \pm 0.09$ & 0.231 \\
\hline Pentadecanoic acid (C15:0) & $0.81 \pm 0.10$ & $1.00 \pm 0.13$ & $0.88 \pm 0.06$ & 0.027 \\
\hline Palmitic acid (C16:0) & $23.87 \pm 2.42$ & $20.46 \pm 2.23$ & $18.42 \pm 1.28$ & 0.003 \\
\hline Palmitoleic acid (C16:1) & $1.15 \pm 0.12$ & $1.16 \pm 0.19$ & $1.03 \pm 0.07$ & 0.323 \\
\hline Heptadecanoic acid (C17:0) & $0.41 \pm 0.04$ & $0.48 \pm 0.07$ & $0.45 \pm 0.05$ & 0.155 \\
\hline Stearic acid (C18:0) & $7.06 \pm 0.59$ & $6.50 \pm 0.80$ & $6.56 \pm 1.22$ & 0.572 \\
\hline Oleic acid (C18:1n-9 cis) & $13.79 \pm 1.30$ & $12.29 \pm 1.14$ & $11.79 \pm 1.63$ & 0.088 \\
\hline Linolelaidic acid (C18:2n-6 trans) & $0.14 \pm 0.04$ & $0.35 \pm 0.02$ & $0.35 \pm 0.03$ & 0.001 \\
\hline Linoleic acid (C18:2n-6 cis) & $1.23 \pm 0.11$ & $0.47 \pm 0.05$ & $0.57 \pm 0.06$ & 0.001 \\
\hline$\gamma$-Linoleic acid (C18:3n-6 cis) & $0.05 \pm 0.00$ & $0.03 \pm 0.01$ & $0.03 \pm 0.00$ & 0.001 \\
\hline Eicosenoic acid (C20:1 cis-11) & $0.27 \pm 0.04$ & $0.55 \pm 0.05$ & $0.73 \pm 0.07$ & 0.001 \\
\hline CLA $(\text { cis- } 9, \text { trans-11) })^{3}$ & $0.58 \pm 0.04$ & $1.71 \pm 0.06$ & $1.35 \pm 0.12$ & 0.001 \\
\hline CLA (cis-12,trans-10) & $0.09 \pm 0.02$ & $0.09 \pm 0.01$ & $0.09 \pm 0.01$ & 0.830 \\
\hline$\alpha$-Linolenic acid (C18:3n-3) & $0.00 \pm 0.00$ & $0.10 \pm 0.01$ & $0.11 \pm 0.01$ & 0.001 \\
\hline Behenic acid (C22:0) & $0.13 \pm 0.01$ & $0.00 \pm 0.00$ & $0.01 \pm 0.02$ & 0.001 \\
\hline Eicosatrienoic acid (C20:3n-6 cis-8,-11,-14) & $0.02 \pm 0.00$ & $0.02 \pm 0.00$ & $0.02 \pm 0.01$ & 0.391 \\
\hline Erucic acid (C22:1n-9) & $0.04 \pm 0.00$ & $0.02 \pm 0.01$ & $0.02 \pm 0.01$ & 0.006 \\
\hline Tricosanoic acid (C23:0) & $0.00 \pm 0.00$ & $0.05 \pm 0.00$ & $0.06 \pm 0.00$ & 0.000 \\
\hline Arachidonic acid (C20:4n-6 cis-5,-8,-11,-14) & $0.00 \pm 0.01$ & $0.07 \pm 0.01$ & $0.07 \pm 0.01$ & 0.001 \\
\hline SFA & $52.49 \pm 4.98$ & $48.53 \pm 5.06$ & $44.97 \pm 3.30$ & 0.058 \\
\hline UFA & $18.86 \pm 1.01$ & $17.69 \pm 1.55$ & $16.86 \pm 1.79$ & 0.132 \\
\hline MUFA & $15.98 \pm 1.52$ & $14.83 \pm 1.40$ & $14.27 \pm 1.71$ & 0.237 \\
\hline PUFA & $2.23 \pm 0.08$ & $2.86 \pm 0.15$ & $2.59 \pm 0.17$ & 0.050 \\
\hline Short chain C4-14 & $20.94 \pm 2.04$ & $20.86 \pm 2.45$ & $19.29 \pm 1.41$ & 0.368 \\
\hline Medium chain C15-17 & $26.24 \pm 2.68$ & $23.09 \pm 2.61$ & $20.79 \pm 1.45$ & 0.007 \\
\hline Long chain C18-24 & $24.18 \pm 1.21$ & $22.26 \pm 2.08$ & $21.76 \pm 2.98$ & 0.222 \\
\hline$n-3$ & $0.00 \pm 0.00$ & $0.10 \pm 0.01$ & $0.11 \pm 0.01$ & 0.001 \\
\hline$n-6$ & $1.43 \pm 0.11$ & $0.95 \pm 0.09$ & $1.05 \pm 0.10$ & 0.001 \\
\hline n-9 & $13.83 \pm 1.31$ & $12.31 \pm 1.16$ & $11.81 \pm 1.64$ & 0.085 \\
\hline Sum CLA & $0.69 \pm 0.04$ & $1.80 \pm 0.06$ & $1.45 \pm 0.13$ & 0.001 \\
\hline $\mathrm{n}-3+\mathrm{CLA}$ & $0.75 \pm 0.04$ & $1.90 \pm 0.06$ & $1.54 \pm 0.13$ & 0.001 \\
\hline$n-3 / n-6$ & $0.00 \pm 0.00$ & $0.10 \pm 0.01$ & $0.10 \pm 0.02$ & 0.001 \\
\hline $\mathrm{n}-6 /(\mathrm{n}-3+\mathrm{CLA})$ & $1.98 \pm 0.07$ & $0.50 \pm 0.03$ & $0.68 \pm 0.09$ & 0.001 \\
\hline Atherogenicity index & $3.44 \pm 0.12$ & $3.56 \pm 0.20$ & $3.40 \pm 0.38$ & 0.583 \\
\hline Thrombogenic index & $4.51 \pm 0.13$ & $4.26 \pm 0.13$ & $4.06 \pm 0.24$ & 0.004 \\
\hline Spreadability index (C16:0/C18:1) & $1.73 \pm 0.08$ & $1.67 \pm 0.10$ & $1.58 \pm 0.20$ & 0.255 \\
\hline
\end{tabular}

${ }^{1}$ Mean and SD of FAME as g/100 g of butter fat of butters derived from cows on different feeding systems. Statistical analysis by one-way ANOVA with post hoc Tukey test.

${ }^{2} \mathrm{GRS}=$ perennial ryegrass; $\mathrm{CLV}=$ perennial ryegrass and white clover. 
(C23:0). Pentadecanoic acid was significantly higher $(P$ $=0.023)$ in GRS butter than in TMR butter. The TMR butter had the highest palmitic acid content, which was greater $(P=0.046)$ than that of the GRS butter and significantly $(P=0.002)$ more than that of the CLV butter. Behenic acid was depleted in pasture-derived butters, whereas behenic acid content of TMR butter was significantly $(P \leq 0.001)$ higher. The GRS and CLV butters had higher concentrations of tricosanoic $(P \leq 0.001)$ acid than TMR butter, which was devoid of the FA.

Among MUFA, eicosenoic acid (C20:1 cis-11) and erucic acid $(\mathrm{C} 22: 1 \mathrm{n}-9)$ varied significantly $(P \leq 0.05)$ between feeding system. Eicosenoic acid was highest in CLV butters, significantly higher than GRS $(P \leq 0.001)$ and TMR $(P<0.001)$ butters. Erucic acid content was highest $(P=0.012)$ in TMR samples.

Significant $(P \leq 0.05)$ differences in PUFA were also recorded between feeding systems for linolelaidic acid (C18:2n-6 trans), linoleic acid (C18:2n-6 cis), $\alpha$-linolenic acid (C18:3n-3), $\gamma$-linoleic acid (C18:3n-6 cis), CLA (C18:2 cis-9,trans-11), and arachidonic acid (C20:4n-6 cis-11,-14,-17).

Linolelaidic acid was highest in pasture-derived butters, significantly $(P \leq 0.001)$ higher than in TMR butter. Linoleic acid was highest in TMR butter, with a greater than 2 -fold increase $(P \leq 0.001)$ in content compared with GRS and CLV concentrations. $\alpha$-Linolenic acid was present at the greatest concentrations in GRS and CLV butters but was almost absent $(P \leq 0.001)$ in TMR samples. $\gamma$-Linoleic acid was highest in TMR butter, and it was significantly $(P=$ 0.01) higher than in GRS and CLV butters. Pasturederived butters had a greater than 2-fold increase in the biologically active isomer of CLA (C18:2 cis9,trans-11) compared with TMR butter. Conjugated linoleic acid was present at the greatest concentration in GRS butter, which had significantly $(P \leq 0.001)$ higher amounts than CLV and TMR butters. The CLV butter CLA content was also significantly higher than that of TMR $(P \leq 0.001)$. Arachidonic acid was absent in TMR butter but present in GRS and CLV butters $(P \leq 0.001)$. The TMR butter had a greater thrombogenicity index score than CLV $(P=0.03)$ and GRS $(P=0.08)$ butters at $4.51 \pm 0.13,4.06 \pm$ 0.24 , and $4.26 \pm 0.13$ scores, respectively. The ratio of C16:0 to C18:1, which has been used as an index for butter spreadability in the past, was highest in TMR butters. Following 6-mo storage at $5^{\circ} \mathrm{C}$, each of the butters had a FFA content $(P>0.05)$ of $0.13 \pm 0.01$, $0.13 \pm 0.01$, and $0.11 \pm 0.02 \mathrm{~g} / 100 \mathrm{~g}$ of butter fat for TMR, GRS, and CLV butters, respectively.

\section{Partial Least Squares Regression}

The PLSR plot of FAME showed clear discrimination of samples according to feeding system (Figure 1). The TMR samples were clustered on the outer right side of the plot; however, the GRS and CLV samples were located on the outer left side. The TMR butter samples were found to be more associated with behenic acid, erucic acid, palmitic acid, and $\gamma$-linoleic and linoleic acids. In contrast, GRS and CLV samples were associated with tricosanoic acid, CLA (C18:2 cis-9,trans-11), arachidonic acid, eicosanoic acid, and linolelaidic acid content, which is in agreement with the FA data shown in Table 1.

\section{Thermal Properties}

Crystallization onset temperature (T-onset) for each of the butters differed significantly between feeding systems (Figure 2 and Table 2). The TMR butters had the highest T-onset at mean $\pm \mathrm{SD}$ of $17.24 \pm 0.30^{\circ} \mathrm{C}$, which was significantly higher than GRS $(P=0.004)$ and $\operatorname{CLV}(P=0.007)$ butters at $15.90 \pm 0.57^{\circ} \mathrm{C}$ and $16.02 \pm 0.67^{\circ} \mathrm{C}$, respectively. No significant difference existed between T-onset of GRS and CLV butters. The cooling profiles of each butter were characterized by 2 exothermic peaks (crystallization peaks) - a first minor peak in energy followed by a second major peak in energy. The first and second peaks of crystallization were recorded at higher temperatures for TMR butters than for pasture-derived butters. The GRS butter's first peak of crystallization temperature occurred at 12.34 $\pm 0.40^{\circ} \mathrm{C}$, which was lower than the peaks for TMR butter $(P=0.11)$ at $14.25 \pm 0.50^{\circ} \mathrm{C}$ and CLV butter at $13.11 \pm 1.39^{\circ} \mathrm{C}$. The TMR butter's second peak of crystallization occurred at $9.26 \pm 0.30^{\circ} \mathrm{C}$, which was significantly higher $(P \leq 0.001)$ than the peaks for GRS and CLV butters at $7.07 \pm 0.44^{\circ} \mathrm{C}$ and $7.03 \pm 0.17^{\circ} \mathrm{C}$, respectively. Enthalpy of crystallization for TMR butters was $28.39 \pm 3.45 \mathrm{~J} / \mathrm{g}$, which was higher $(P>0.05)$ than that of GRS butter at $26.06 \pm 1.06 \mathrm{~J} / \mathrm{g}$ and CLV butter at $25.92 \pm 2.92 \mathrm{~J} / \mathrm{g}$. No significant difference existed in the T-offset of the butters; however, T-offset was recorded at higher temperatures for TMR butter than for GRS and CLV butters at $36.28 \pm 0.24^{\circ} \mathrm{C}, 35.27$ $\pm 0.48^{\circ} \mathrm{C}$, and $35.81 \pm 1.29^{\circ} \mathrm{C}$, respectively.

\section{Color and trans- $\beta-$ Carotene Analysis}

No significant difference was observed in the $\mathrm{L}^{*}$ and $a^{*}$ values of the butters at each of the sampling time points. However, significant differences were recorded 


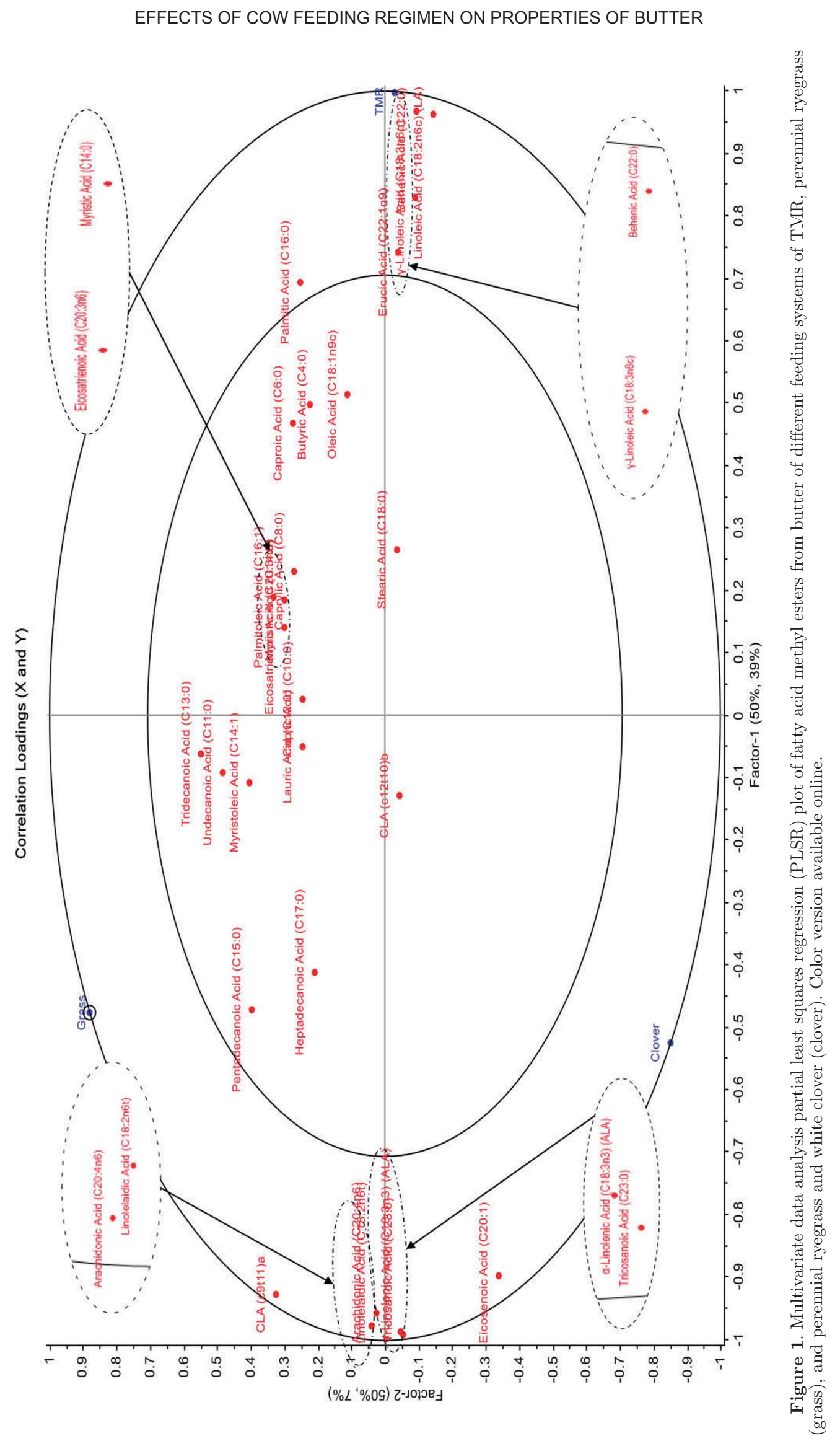

Journal of Dairy Science Vol. 99 No. 12, 2016 


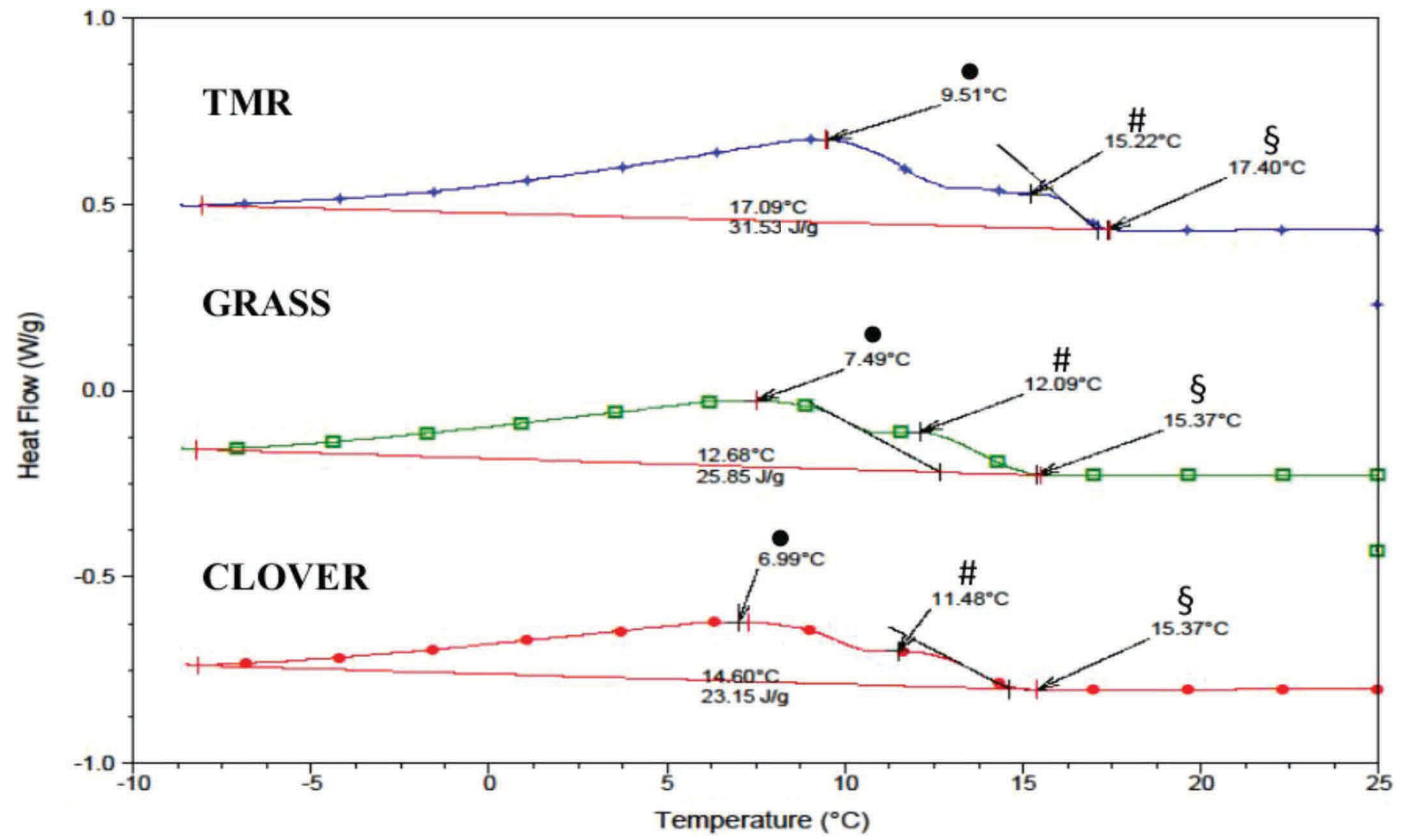

Figure 2. Relationship between the cow feeding system and the crystallization temperature of butter determined by differential scanning calorimetry (DSC). Example of DSC cooling chromatograms of butter derived from TMR, perennial ryegrass (grass), and perennial ryegrass and white clover (clover), indicating temperature at beginning of fat crystallization (T-onset; §) and first (\#) and second (-) peak crystallization temperatures. Color version available online.

for the $b^{*}$ value of the butters from each of the feeding systems. Average (mean $\pm \mathrm{SD}$ ) $\mathrm{b}^{*}$ value for GRS butter was greater than for that of $\operatorname{CLV}(P=0.025)$ and TMR $(P<0.001)$ samples, with scores of 42.06 $\pm 3.66,38.87 \pm 3.21$, and $29.91 \pm 2.26$, respectively, indicating that pasture-derived butters were more yellow in color than TMR butter, which directly correlates with trans- $\beta$-carotene results (Figure 3 ). The CLV but- ter $\mathrm{b}^{*}$ values were also significantly higher than those for TMR butter $(P<0.001)$. Storage time also had a significant effect on the butters' $\mathrm{a}^{*}(P=0.002)$ and $\mathrm{b}^{*}$ values $(P<0.001)$. GRS butter's a* value increased over 6-mo storage from $-3.30 \pm 0.45$ at $\mathrm{d} 7$ to -2.47 \pm 0.20 at 6 mo, indicating that the butter was becoming more red in color during storage. The $b^{*}$ values for GRS and CLV butters also changed, dropping from

Table 2. Relationship between cow feeding system and crystallization and final melting temperature of butter determined by differential scanning calorimetry

\begin{tabular}{|c|c|c|c|c|}
\hline \multirow[b]{2}{*}{ Item } & \multicolumn{3}{|c|}{ Feeding system ${ }^{1}$} & \multirow[b]{2}{*}{$P$-value } \\
\hline & TMR & GRS & CLV & \\
\hline T-onset ${ }^{2}\left({ }^{\circ} \mathrm{C}\right)$ & $17.24 \pm 0.30$ & $15.90 \pm 0.57$ & $16.02 \pm 0.67$ & 0.002 \\
\hline First peak crystallization $\left({ }^{\circ} \mathrm{C}\right)$ & $14.25 \pm 0.50$ & $12.34 \pm 0.40$ & $13.11 \pm 1.39$ & 0.013 \\
\hline Second peak crystallization $\left({ }^{\circ} \mathrm{C}\right)$ & $9.26 \pm 0.30$ & $7.07 \pm 0.44$ & $7.03 \pm 0.17$ & 0.001 \\
\hline Enthalpy of crystallization $(\mathrm{J} / \mathrm{g})$ & $28.39 \pm 3.45$ & $26.06 \pm 1.06$ & $25.92 \pm 2.92$ & 0.291 \\
\hline T-offset ${ }^{3}\left({ }^{\circ} \mathrm{C}\right)$ & $36.28 \pm 0.24$ & $35.27 \pm 0.48$ & $35.81 \pm 1.29$ & 0.178 \\
\hline
\end{tabular}

${ }^{1}$ GRS $=$ perennial ryegrass; CLV $=$ perennial ryegrass and white clover.

${ }^{2} \mathrm{~T}$-onset $=$ temperature at beginning of fat crystallization.

${ }^{3} \mathrm{~T}$-offset $=$ final melting temperature. 
$42.49 \pm 0.98$ to $36.14 \pm 0.98$ for GRS and $38.68 \pm 0.97$ to $34.05 \pm 1.65$ for CLV, indicating that butters were becoming more blue (pale) during storage at $4^{\circ} \mathrm{C}$. The GRS butters had the highest trans- $\beta$-carotene content at $5.16 \pm 0.22 \mathrm{mg} / \mathrm{kg}$ of butter, which was significantly higher than the content of TMR $(P<0.001)$ and CLV $(P=0.019)$ butters, which was $2.27 \pm 0.13 \mathrm{mg} / \mathrm{kg}$ and $3.99 \pm 0.46 \mathrm{mg} / \mathrm{kg}$, respectively. A significantly positive correlation existed between the increase in $b^{*}$ scores of butters and their respective trans- $\beta$-carotene content $(\mathrm{r}$ $=0.899, P<0.001 ;$ Figure 3).

A
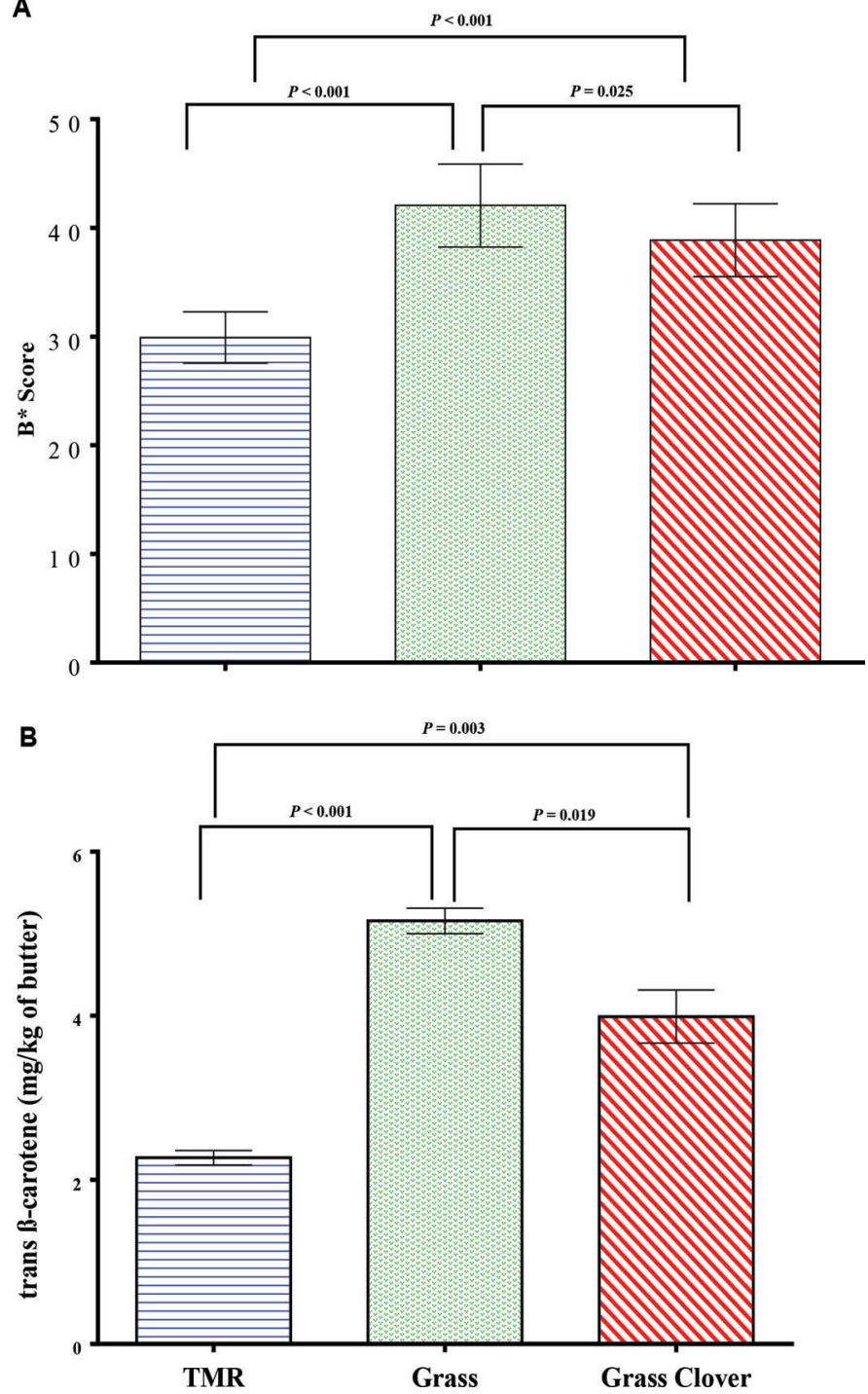

Figure 3. Relationship between cow feeding systems [TMR, perennial ryegrass (grass), and perennial ryegrass and white clover (grass clover)] and the color scores of butter in the blue-yellow axis $\left(b^{*}\right)$ and the trans- $\beta$-carotene content of butter. Trans- $\beta$-carotene and $\mathrm{b}^{*}$ values appear to be positively correlated $(r=0.899)$; they are highest in pasture and lowest in TMR butters. Color version available online.

\section{Texture Analysis}

Refrigerated Temperature. At $5^{\circ} \mathrm{C}$, the difference in hardness of butters from different feeding systems was not significant $(P=0.058)$. Hardness of each of the butters did increase significantly $(P<0.001)$ throughout the storage period. The hardness of TMR butter increased by $19.44 \mathrm{~N}$ between month (M)1 and M6, with measurements (mean \pm SD) of $37.95 \pm 4.23$ $\mathrm{N}$ and $57.39 \pm 4.12 \mathrm{~N}$, respectively. The hardness of CLV butter increased by $15.95 \mathrm{~N}$ from M1 to M6, with measurements of $31.61 \pm 4.40 \mathrm{~N}$ and $47.57 \pm 7.42 \mathrm{~N}$, respectively. The hardness of GRS butter was the least affected by storage, increasing by $9.5 \mathrm{~N}$ from M1 to M6, with measurements of $33.09 \pm 3.81 \mathrm{~N}$ and $42.60 \pm 5.11$ $\mathrm{N}$, respectively.

Room Temperature. At $20^{\circ} \mathrm{C}$, TMR butter appeared to be hardest throughout the 6-mo storage period, and it was significantly $(P=0.001)$ harder than CLV and GRS butters. The hardness of each of the butters also increased significantly $(P \leq 0.001)$ over the storage period when measured at $20^{\circ} \mathrm{C}$. The hardness of TMR butter increased by $5.82 \mathrm{~N}$ from M1 to M6 with measurements of $7.43 \pm 1.22 \mathrm{~N}$ and $13.25 \pm 0.60$ $\mathrm{N}$, respectively. The hardness of GRS butter increased by $7.11 \mathrm{~N}$ from M1 to M6, with measurements of 4.36 $\pm 1.11 \mathrm{~N}$ and $11.47 \pm 1.21 \mathrm{~N}$, respectively. The CLV butter was the softest at $20^{\circ} \mathrm{C}$, increasing by $7.02 \mathrm{~N}$ from M1 to M6, with measurements of $3.64 \pm 0.14 \mathrm{~N}$ and $10.66 \pm 0.51 \mathrm{~N}$, respectively.

\section{Sensory Analysis}

Panelist data scores (mean \pm SD) for sensory analysis of butters are shown in Table 3. Butter from the GRS system scored significantly higher for the hedonic sensory descriptors, liking of appearance $(P=0.004)$ and liking of flavor $(P=0.030)$, compared with the TMR butter samples. Significant differences were recorded for ranking descriptive analysis between each of the butter samples. The GRS butter scored significantly higher than TMR butter samples for color $(P=0.007)$, diacetyl aroma $(P=0.015)$, diacetyl flavor $(P=0.016)$, and cream flavor $(P=0.011)$. The CLV butter samples also scored significantly higher for texture $(P<0.02)$ in comparison with the TMR samples. The CLV and GRS butter samples were not significantly different for any of the other hedonic or ranking sensory descriptor attributes (Figure 4).

\section{Volatile Analysis}

Volatile analysis of butters by GC-MS revealed 25 compounds in total within all of the butters (Table 
Table 3. Relationship between cow feeding system and butter characteristics determined by sensory analysis

\begin{tabular}{|c|c|c|c|c|}
\hline \multirow[b]{2}{*}{ Sensory attribute ${ }^{1}$} & \multicolumn{3}{|c|}{ Panelists' scores $^{2}$} & \multirow[b]{2}{*}{$P$-value ${ }^{3}$} \\
\hline & TMR & GRS & CLV & \\
\hline \multicolumn{5}{|l|}{ Hedonic } \\
\hline Liking of appearance & $5.93 \pm 1.55$ & $7.28 \pm 1.55$ & $6.81 \pm 1.17$ & 0.005 \\
\hline Liking of aroma & $5.93 \pm 1.65$ & $6.65 \pm 1.39$ & $6.39 \pm 1.17$ & 0.197 \\
\hline Liking of flavor & $5.59 \pm 0.92$ & $6.57 \pm 1.70$ & $5.93 \pm 1.28$ & 0.035 \\
\hline Liking texture & $5.82 \pm 1.42$ & $6.61 \pm 1.53$ & $6.14 \pm 1.08$ & 0.130 \\
\hline Overall consumer acceptability & $5.64 \pm 1.03$ & $6.39 \pm 1.54$ & $5.74 \pm 1.20$ & 0.087 \\
\hline \multicolumn{5}{|l|}{ Intensity } \\
\hline Color & $5.94 \pm 1.58$ & $7.23 \pm 1.56$ & $6.76 \pm 1.17$ & 0.009 \\
\hline Diacetyl aroma & $3.29 \pm 1.68$ & $4.71 \pm 1.87$ & $3.91 \pm 1.68$ & 0.020 \\
\hline Artificial butter aroma & $3.04 \pm 1.32$ & $2.71 \pm 1.58$ & $3.06 \pm 1.19$ & 0.604 \\
\hline Nutty aroma & $1.73 \pm 1.06$ & $2.04 \pm 1.04$ & $1.95 \pm 0.87$ & 0.520 \\
\hline Rancid aroma & $1.49 \pm 1.06$ & $1.80 \pm 1.13$ & $1.82 \pm 1.37$ & 0.552 \\
\hline Grassy aroma & $1.71 \pm 0.99$ & $1.83 \pm 1.02$ & $1.77 \pm 0.87$ & 0.909 \\
\hline Cardboard aroma & $1.14 \pm 0.93$ & $1.69 \pm 1.02$ & $1.54 \pm 1.19$ & 0.164 \\
\hline Off aroma & $1.47 \pm 1.19$ & $1.58 \pm 1.13$ & $1.39 \pm 1.08$ & 0.828 \\
\hline Barnyard aroma & $1.56 \pm 1.20$ & $2.08 \pm 1.20$ & $2.16 \pm 1.29$ & 0.181 \\
\hline Fecal aroma & $0.64 \pm 0.68$ & $0.81 \pm 0.73$ & $0.83 \pm 0.81$ & 0.630 \\
\hline Sweet taste & $2.79 \pm 1.21$ & $2.67 \pm 1.12$ & $3.19 \pm 1.26$ & 0.274 \\
\hline Salt taste & $4.33 \pm 1.89$ & $4.89 \pm 2.05$ & $4.92 \pm 1.36$ & 0.425 \\
\hline Acidic taste & $2.65 \pm 1.62$ & $2.42 \pm 1.40$ & $3.06 \pm 1.68$ & 0.355 \\
\hline Bitter taste & $2.17 \pm 1.29$ & $2.21 \pm 1.23$ & $2.48 \pm 1.55$ & 0.676 \\
\hline Firmness in mouth & $2.80 \pm 1.57$ & $3.43 \pm 1.33$ & $3.56 \pm 1.40$ & 0.146 \\
\hline Texture & $3.42 \pm 1.12$ & $3.87 \pm 1.29$ & $4.41 \pm 1.44$ & 0.029 \\
\hline Melt in mouth & $5.18 \pm 1.71$ & $5.55 \pm 1.65$ & $4.96 \pm 1.99$ & 0.497 \\
\hline Diacetyl flavor & $2.95 \pm 1.64$ & $4.33 \pm 1.75$ & $3.78 \pm 1.79$ & 0.021 \\
\hline Cream flavor & $3.43 \pm 1.44$ & $4.55 \pm 1.31$ & $4.13 \pm 1.27$ & 0.015 \\
\hline Artificial butter flavor & $2.33 \pm 1.17$ & $2.32 \pm 1.33$ & $2.65 \pm 1.16$ & 0.558 \\
\hline Nutty flavor & $1.32 \pm 0.94$ & $1.78 \pm 1.00$ & $1.68 \pm 1.05$ & 0.235 \\
\hline Rancid flavor & $1.71 \pm 0.92$ & $1.52 \pm 1.14$ & $1.56 \pm 1.21$ & 0.826 \\
\hline Cardboard flavor & $1.35 \pm 0.99$ & $1.56 \pm 1.17$ & $1.67 \pm 1.17$ & 0.598 \\
\hline Off flavor & $1.42 \pm 1.02$ & $1.43 \pm 1.37$ & $1.73 \pm 1.62$ & 0.655 \\
\hline Barnyard flavor & $1.61 \pm 1.24$ & $1.07 \pm 1.08$ & $1.46 \pm 1.14$ & 0.243 \\
\hline
\end{tabular}

4). These included 6 aldehydes (2-methyl butanol, pentanal, hexanal, heptanal, benzaldehyde, and nonanal), 5 ketones (acetone, 2-butanone, 2-pentanone, 2-heptanone, and 2-nonanone), 2 alcohols (1-pentanol and 2-methyl-1-butanol), 3 acids (acetic acid, butanoic acid, and hexanoic acid), 5 hydrocarbons (toluene, ethylbenzene, 3 -ethyl toluene, $m$-xylene, and $o$-xylene), 3 esters (ethyl acetate, butyl acetate, and ethyl octanoate), and 1 terpene compound ( $\beta$-pinene).

Higher intensities of acetone were detected in CLV butter samples than in TMR $(P=0.015)$ and GRS $(P=$ 0.004 ) butters. 2-Butanone was present at significantly $(P=0.012)$ higher intensity in TMR butters than GRS butters. The alcohol 1-pentanol was detected at significantly higher intensities in CLV butter samples than in GRS $(P=0.015)$ and TMR $(P=0.004)$ butters. The hydrocarbon toluene was significantly correlated with pasture-derived butters, more than that of TMR ( $P$ $\leq 0.001)$ and was highest in CLV-derived samples. Fi- nally, $\beta$-pinene intensity was significantly lower in TMR samples than in GRS and CLV samples $(P=0.003)$. The PLSR plot of butter volatiles also corresponds with these significant differences and shows clear separation of samples according to feeding system, with toluene appearing to be significantly correlated with GRS- and CLV-derived samples (Figure 5).

\section{DISCUSSION}

In this study, we investigated the effects of 3 widely practiced feeding systems on the characteristics, composition, quality, and consumer perception of midlactation sweet cream butter. Fatty acid methyl esters differed significantly in butters from each of the feeding systems, following similar trends found with the raw milks from this study, reported in the companion manuscript (O'Callaghan et al., 2016). These results highlight that only minor changes occur in milk FA 


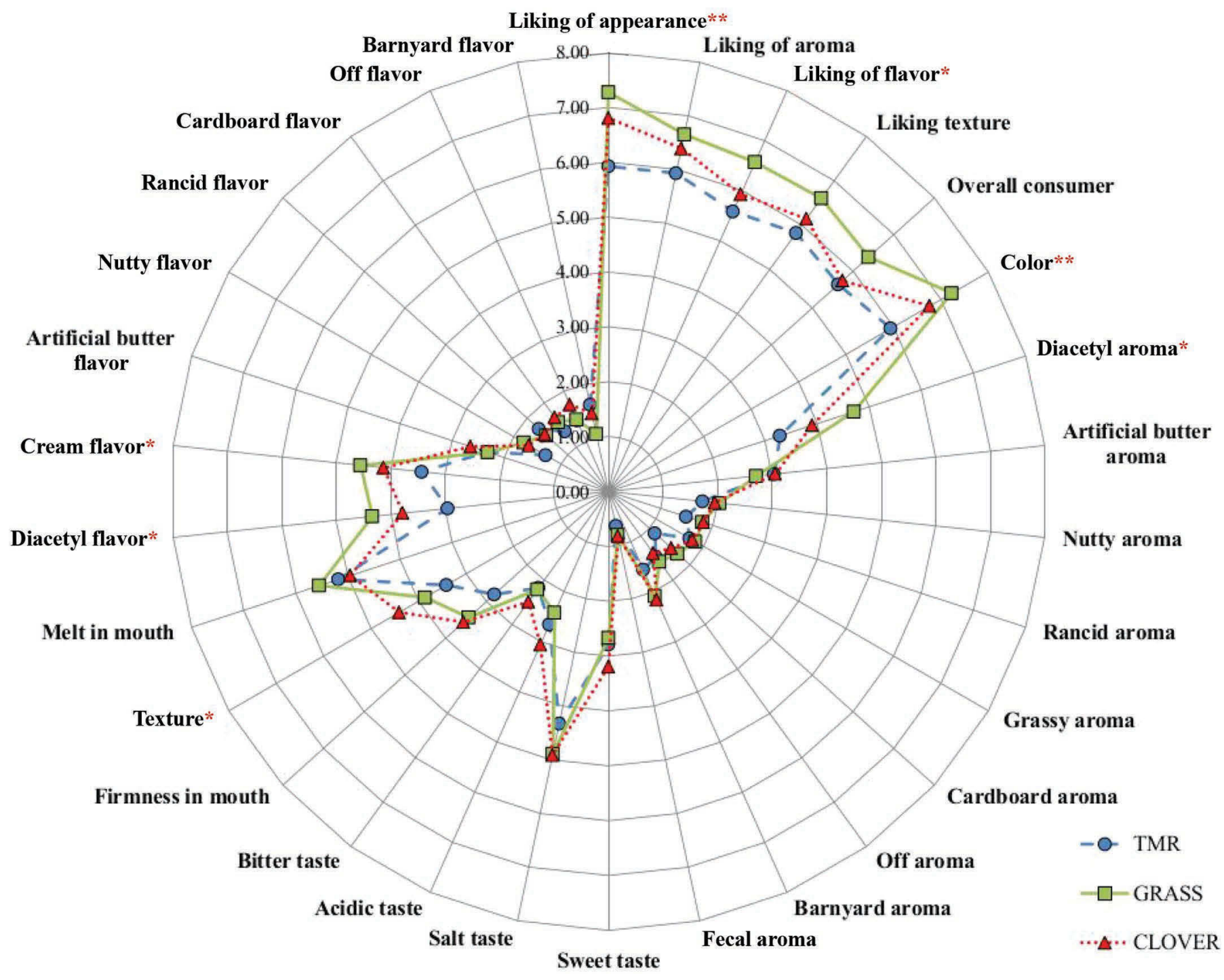

Figure 4. Sensory analysis of butter derived from different feeding systems of TMR, perennial ryegrass (grass), and perennial ryegrass and white clover (clover). Definition of sensory attributes available in Supplemental Table S1 (http://dx.doi.org/10.3168/jds.2016-11271). Statistical analysis by one-way ANOVA, ${ }^{*} P<0.05, * * P<0.01$. Color version available online.

triglyceride composition during the butter production process, which has been reported in the past (Baer et al., 2001; Bobe et al., 2003).

The atherogenicity and thrombogenicity indices outlined by Ulbricht and Southgate (1991) are dietary risk indices for cardiovascular disease. Consumption of dairy products with lower atherogenicity and thrombogenicity index scores is therefore more favorable to consumer health than their high atherogenicity and thrombogenicity score counterparts, with reported reductions in both total and low-density lipoprotein cholesterol in humans consuming modified butter (Poppitt et al., 2002). The TMR butters in this study had greater thrombogenicity index scores than GRS butter and significantly greater than CLV butter, at 4.51, 4.06, and 4.26, respectively. Greater thrombogenicity index scores in TMR butter could be attributed to increased palmitic acid and n- 6 PUFA content in TMR butter compared with GRS and CLV butters, which had significantly less palmitic acid and n-6 FA and significantly more n-3 FA. No significant difference was found for atherogenicity index scores of butters; however, lower atherogenicity index scores in fresh grass-derived milks has been reported in the past by Couvreur et al. (2006) in a comparison of the effects of TMR and 100\% fresh grass feeding systems.

Through in vitro and rodent model research, CLA (cis-9,trans-11) has primarily been associated with 


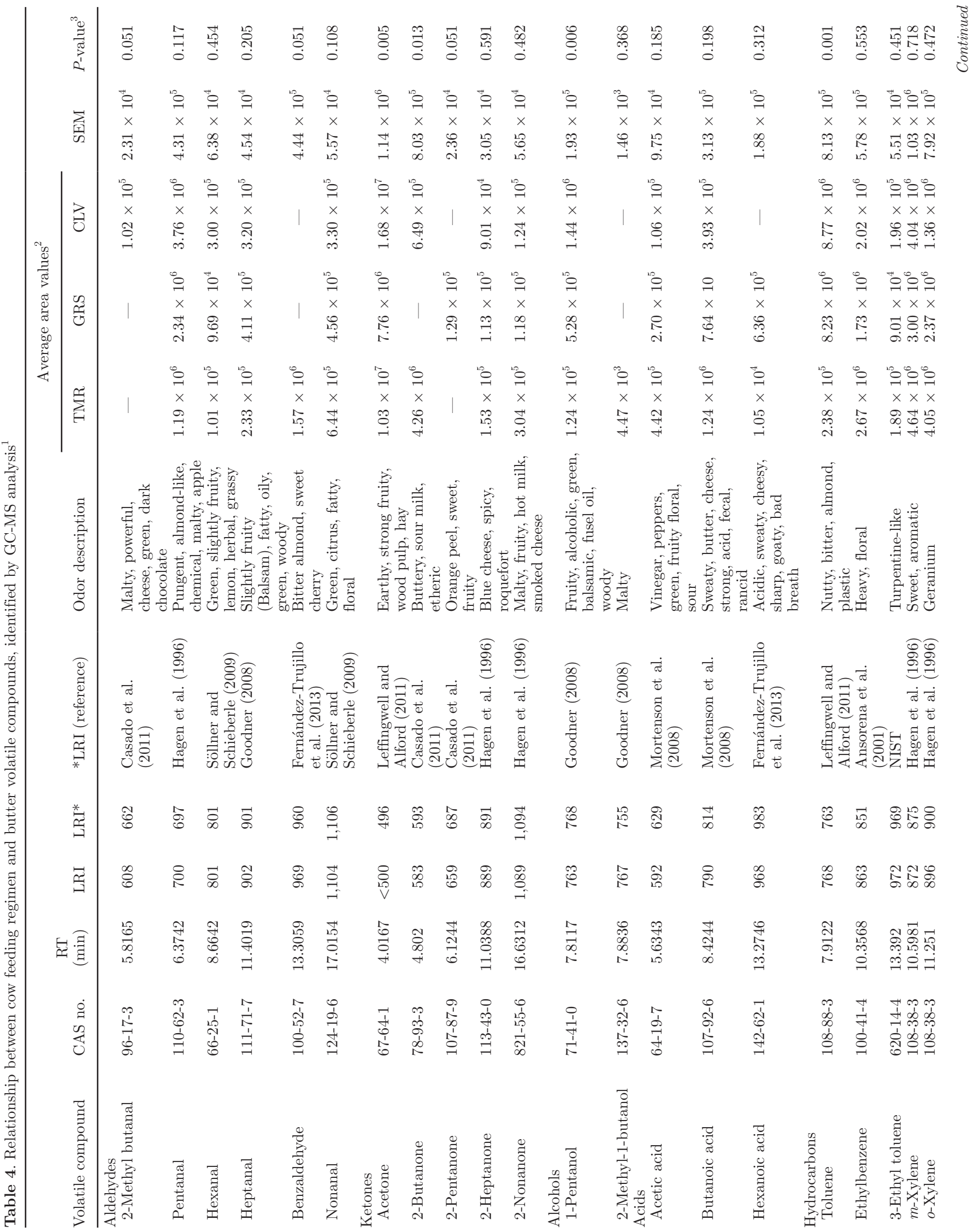


the prevention of many lifestyle-related disorders and metabolic syndromes because of its antihypertensive, anti-obesity, antidiabetic, and anticarcinogenic properties (Koba and Yanagita, 2014). Dairy products derived from ruminants are a natural source of CLA, and their feeding regimen is a major factor affecting the concentration of CLA in milk and dairy products (Kelly et al., 1998; Elgersma et al., 2006). Several studies in the past have reported the positive linear response of CLA concentration in cows' milk to their intake of fresh pasture (Couvreur et al., 2006). Our study demonstrated that butters derived from pasture-based systems contained greater than 2-fold concentrations of CLA (cis-9,trans-11) compared with TMR butters (1.71 and $1.35 \mathrm{~g} / 100 \mathrm{~g}$ of butter fat for GRS and CLV, respectively, versus $0.58 \mathrm{~g} / 100 \mathrm{~g}$ of butter fat for TMR). However, this increase in CLA content is in fact lower than that reported by Mohammed et al. (2009), who compared the effects of grazing perennial ryegrass and consumption of grass silage with CLA contents of 2.07 and $0.54 \%$ of total FA, respectively. Lerch et al. (2012) also demonstrated that the supplementation of a diet based on grass silage and hay with extruded linseed oil and rapeseed oil had a beneficial effect on milk CLA concentration.

Free fatty acids are produced during hydrolytic oxidation and are typically used as a qualitative reference of milk, butter, and other dairy products (Mannion et al., 2015). The FFA can also contribute to the sensory aspects of dairy products, with elevated levels of short chain FFA being responsible for rancidity (Deeth, 2006). The FFA values of each of the butters after 6 mo of storage at $5^{\circ} \mathrm{C}$ were not significantly different. This result is consistent with FFA values reported by Krause et al. (2008), who also reported that FFA values of butters remained relatively stable for up to 6 mo before a slight increase in FFA was recorded.

Hardness and spreadability are inversely related characteristics of butters and potentially the most important aspects of texture and rheological influence on consumer perception (Wright et al., 2001). Hardness of pasture-derived butters was decreased at $20^{\circ} \mathrm{C}$ compared with that of TMR butter, and this difference could be attributed to variations in butter FA content; pasture butter's lower SFA content, which appeared to be trending toward significance $(P=0.058)$; and significantly lower concentrations of palmitic acid. The textural and rheological properties of milk fats are strongly dependent on the thermal and structural properties of the triglycerides (Lopez et al., 2001). Differences in the FA composition of butters result in alterations of butter crystallization and melting point. Differential scanning calorimetry analysis (Figure 2) showed that the onset of crystallization (change from 


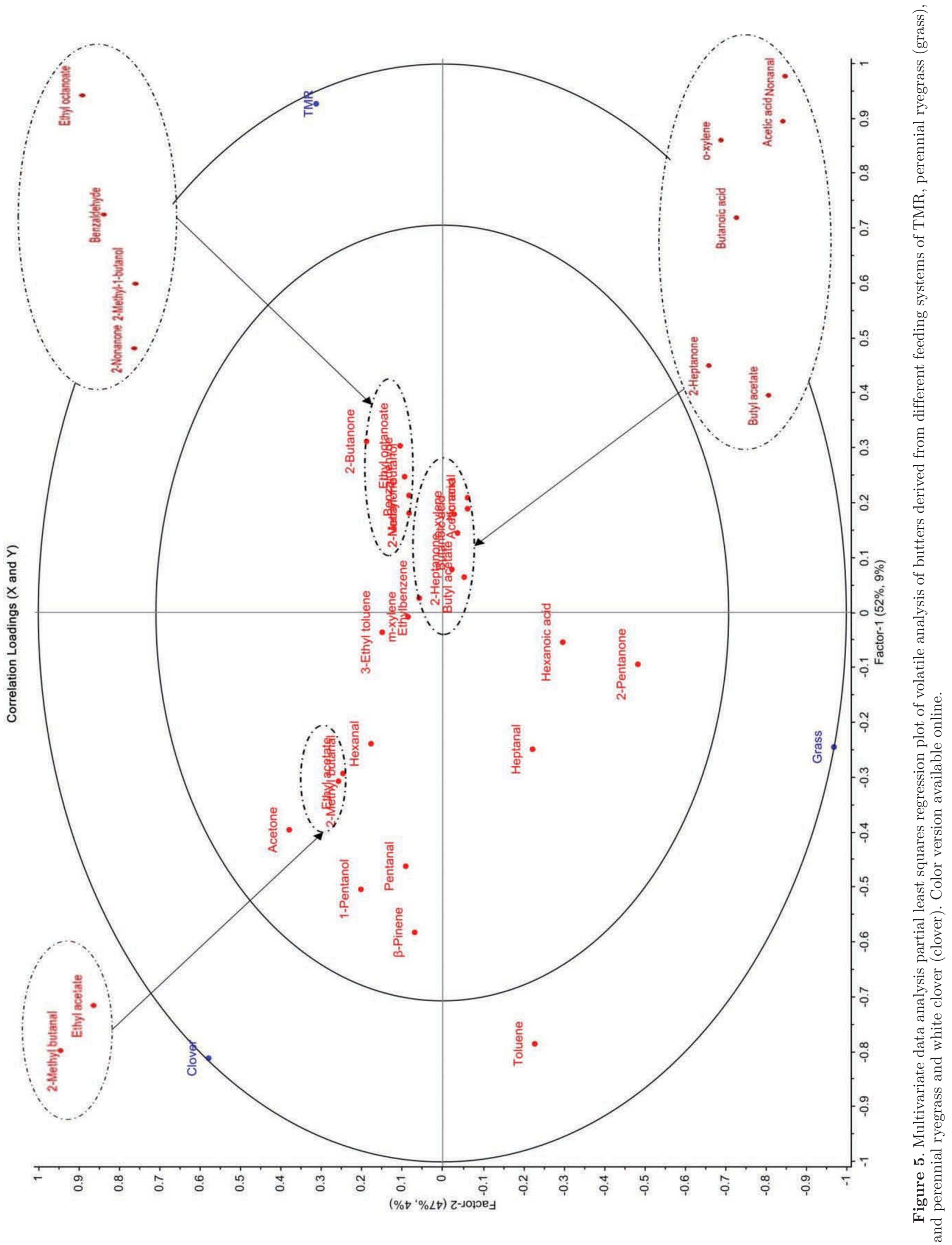


a liquid to solid state) for TMR butters occurred at significantly higher temperatures than pasture-derived butters, which would contribute to increased hardness results at room temperature. In fact, Brunner (1974) initially reported that $80 \%$ of the variation in butter texture could be attributed to differences in milk FA. This finding also agrees with sensory ranking descriptive analysis scores for GRS and CLV butters, which scored higher for the texture attribute $(P=0.028)$. Similar studies have reported significant differences in the spreadability index of butters from pasture versus TMR (Couvreur et al., 2006). Although this trend was observed in this study, spreadability index scores were not significantly different between feedings systems. During 6-mo storage, the hardness of butters increased significantly, which was also reported by Krause et al. (2008) and has been attributed to changes in the solidification of triglycerides during storage (Kulkarni and Ramamurthy, 1985).

The $\beta$-carotene content was highest in GRS butter and lowest in TMR butter. The $\beta$-carotene content of milk can vary depending on cow feeding system and is dependent on dietary supply of the pigment to the cow. Fresh forages have a greater $\beta$-carotene supply than their silage and concentrate counterparts because the ensiling process and the processing of feeds for concentrates typically deplete or destroy many carotenoids. As a result, most concentrates fed to cows on a TMR system are low in $\beta$-carotene (Noziere et al., 2006). $\beta$-Carotene has many beneficial attributes such as being a precursor to vitamin $\mathrm{A}$, which has been inversely associated with cancer risk and also has antioxidant properties particularly involved in preventing photooxidation of high-fat dairy products (Cooper, 2004; Mortensen et al., 2004).

The carotenoid content also has a major effect on the color of dairy products, particularly high-fat dairy products such as butter, by imparting a yellow color. This yellow color carries consumer perceptions of "fresh grass feeding" and thus trans- $\beta$-carotene content of dairy products has been suggested in the past as a potential indicator for verification of products from grazing pasture systems (Prache et al., 2002). This yellow color can in turn be beneficial as a marketing attribute; however, yellow color has also been reported in the past to be a negative feature when exporting to color-sensitive markets such as the Middle East (Keen and Wilson, 1992). GRS- and CLV-derived butters had significantly higher $\mathrm{b}^{*}$ values compared with TMR butters. Indeed, higher $b^{*}$ values of butter were significantly correlated with higher trans- $\beta$-carotene content $(\mathrm{r}=0.899)$, further confirming the hypothesis by Prache et al. (2002) for the use of $\beta$-carotene as a verification method of pasture-derived dairy products.
Direct analysis of the headspace of butters provides a representative view of the volatiles relative to the olfactory receptors (Peterson and Reineccius, 2003). The GC-MS analysis of our butters revealed 25 compounds present in butters from each feeding system, 5 of which differed significantly. Among the ketone compounds, acetone (earthy, strong fruity, wood pulp, hay) was significantly correlated with CLV-derived samples over that of GRS and TMR butters, while 2-butanone (buttery, sour milk, etheric) was greatest in TMR-derived samples. Acetone and 2-butanone have been reported in the past in milk and to originate from the cows' feed (Marsili, 2003). 1-Pentanol (fruity, alcoholic, green, balsamic, fusel oil, woody) was greater in pasture-derived samples than in TMR butter, and CLV-derived butters had significantly greater intensities of the primary alcohol than GRS and TMR samples. 1-Pentanol is derived from the aldehyde pentanal, and its concentrations correlate with those of its aldehyde source, which was also greater in pasture-derived samples and highest in CLV samples. Straight-chain aldehydes such as pentanal are reported to be derived from lipid degradation (Moio et al., 1993; Toso et al., 2002). Similar results were seen by Villeneuve et al. (2013) who reported increased 1-pentanol in pasture milks compared with hay-derived milks. The terpene compound $\beta$-pinene (herbaceous) intensity was significantly greater in pasture-derived samples than in TMR butter, and it was greatest in CLVderived samples. Terpenes also originate from the feed and would have been transferred into the cows' milk. Toluene (nutty, bitter, almond, plastic) concentrations were significantly higher $(P \leq 0.001)$ in pasture-derived butters than in TMR butters, which was also reported by Villeneuve et al. (2013), who examined the effects on milk from timothy feeding of cows as hay, pasture, or silage. Toluene in dairy products has previously been considered a contaminant from the atmosphere or packaging (Henneberry et al., 2016). However, toluene may be more likely to be present in pasture-derived products as a product of $\beta$-carotene degradation (Daun, 2005) because area values for toluene correlate with increased trans- $\beta$-carotene concentrations of the butters from pasture feeding systems.

Multivariate data analysis using PLSR of butter FA triglyceride contents showed clear separation of butters by feeding system being used similar to the raw milks of this study previously reported (O'Callaghan et al., 2016). Overall, this analysis demonstrates that the FA composition of butters from TMR diets and pasturebased diets in this study were quite distinct, but the GRS and CLV pasture diets were much less differentiated. These data further indicate that FA profiling could potentially be used for verification of dairy products derived from the milk of cows consuming a fresh 
pasture-only diet. This possibility is in agreement with Capuano et al. (2014), who concluded that FA profiling might be used for the verification of fresh grass feeding of cows.

\section{CONCLUSIONS}

This study evaluated the effects of 3 widely practiced feeding systems of cows on the characteristics, quality, and consumer perception of butter. Feeding system resulted in significant differences in FA compositions. Such alterations in the FA compositions contributed to significant differences in textural, thermal, sensory, and volatile properties of butters. Pasture-derived (GRS and CLV) systems produced butters with improved nutritional aspects, including lower thrombogenicity index scores and significantly higher concentrations of CLA (cis-9,trans-11) and $\beta$-carotene. Sensory panelist data revealed significantly higher scores for GRS-derived butter in several attributes including "liking" of appearance, flavor, and color. Volatile analysis of butters by GC-MS revealed 25 different compounds from each of the butters, 5 of which differed significantly based on feeding regimen, including acetone, 2-butanone, 1 -pentenol, toluene, and $\beta$-pinene. Toluene concentrations were significantly higher in pasture-derived butters than in TMR butters. Finally, FA profiling coupled with multivariate data analysis showed clear separation of butters derived from grazed pasture diets compared to those from TMR systems, offering further insight into the ability to verify such pasture-derived dairy products by FA profiling.

\section{ACKNOWLEDGMENTS}

This publication is based on research conducted with the financial support of Science Foundation Ireland (SFI) under grant number SFI/12/RC/2273 and the Dairy Levy Fund administered by Dairy Research Ireland. Tom F. O'Callaghan is the recipient of a Teagasc Walsh Fellowship award. The valuable input of Elaine Patterson and David Mannion (Teagasc Moorepark, Ireland) is gratefully acknowledged. Technical assistance over the course of the experiment from Tim Coakley and John O'Reilly is greatly appreciated. The input of Sean Lacey (Department of Mathematics, Cork Institute of Technology, Ireland) for statistical analysis is very much appreciated. The authors sincerely thank the technical and farm staff at Moorepark for their excellent care of the experimental cows and assistance during the experiment.

\section{REFERENCES}

Ansorena, D., O. Gimeno, I. Astiasaran, and J. Bello. 2001. Analysis of volatile compounds by GC-MS of a dry fermented sausage: Chorizo de Pamplona. Food Res. Int. 34:67-75.

Armas, L. A., C. P. Frye, and R. P. Heaney. 2016. Effect of cow's milk on human health. Pages 131-150 in Beverage Impacts on Health and Nutrition. Springer International Publishing, Cham, Switzerland

Baer, R. J., J. Ryali, D. J. Schingoethe, K. M. Kasperson, D. C. Donovan, A. R. Hippen, and S. T. Franklin. 2001. Composition and properties of milk and butter from cows fed fish oil. J. Dairy Sci. 84:345-353.

Beaulieu, J. C., and C. C. Grimm. 2001. Identification of volatile compounds in cantaloupe at various developmental stages using solid phase microextraction. J. Agric. Food Chem. 49:1345-1352.

Benbrook, C. M., G. Butler, M. A. Latif, C. Leifert, and D. R. Davis. 2013. Organic production enhances milk nutritional quality by shifting fatty acid composition: A United States-wide, 18-month study. PLoS One 8:e82429.

Bendall, J. G. 2001. Aroma compounds of fresh milk from New Zealand cows fed different diets. J. Agric. Food Chem. 49:4825-4832.

Bobe, G., E. Hammond, A. Freeman, G. Lindberg, and D. Beitz. 2003. Texture of butter from cows with different milk fatty acid compositions. J. Dairy Sci. 86:3122-3127.

Brunner, J. 1974. Physical equilibria in milk: The lipid phase. Pages 474-602 in Fundamentals of Dairy Chemistry. B. H. Webb, A. H. Johnson, and J. A. Alford, ed. AVI, Westport, CT.

Capuano, E., G. Van der Veer, R. Boerrigter-Eenling, A. Elgersma, J. Rademaker, A. Sterian, and S. M. Van Ruth. 2014. Verification of fresh grass feeding, pasture grazing and organic farming by cows farm milk fatty acid profile. Food Chem. 164:234-241.

Casado, E. M., J. J. Cordoba, M. J. Andrade, and M. Rodríguez. 2011. Design of a method to evaluate yeasts to be used as starter cultures in dry-cured meat products. Czech J. Food Sci. 29:463-470.

Cavanagh, D., K. N. Kilcawley, M. G. O’Sullivan, G. F. Fitzgerald, and O. McAuliffe. 2014. Assessment of wild non-dairy lactococcal strains for flavour diversification in a mini-Gouda type cheese model. Food Res. Int. 62:432-440.

Chilliard, Y., A. Ferlay, and M. Doreau. 2001. Effect of different types of forages, animal fat or marine oils in cow's diet on milk fat secretion and composition, especially conjugated linoleic acid (CLA) and polyunsaturated fatty acids. Livest. Prod. Sci. 70:31-48.

Chilliard, Y., F. Glasser, A. Ferlay, L. Bernard, J. Rouel, and M. Doreau. 2007. Diet, rumen biohydrogenation and nutritional quality of cow and goat milk fat. Eur. J. Lipid Sci. Technol. 109:828855 .

Commission Internationale de l'Éclairage. 1996. Colour Measurement. Doc. 15. CIE, Fontenayaux- Roses, France.

Cooper, D. A. 2004. Carotenoids in health and disease: Recent scientific evaluations, research recommendations and the consumer. J. Nutr. 134:221S-224S.

Couvreur, S., C. Hurtaud, C. Lopez, L. Delaby, and J.-L. Peyraud. 2006. The linear relationship between the proportion of fresh grass in the cow diet, milk fatty acid composition, and butter properties. J. Dairy Sci. 89:1956-1969.

Daun, H. 2005. Produce color and appearance. Pages 191-219 in Produce Degradation: Pathways and Prevention. O. Lamikanra and S. H. Imam, ed. CRC Press, Boca Raton, FL.

De Jong, C., and H. T. Badings. 1990. Determination of free fatty acids in milk and cheese procedures for extraction, clean up, and capillary gas chromatographic analysis. J. High Resolut. Chromatogr. 13:94-98.

Deeth, H. C. 2006. Lipoprotein lipase and lipolysis in milk. Int. Dairy J. 16:555-562.

Egan, M., M. Lynch, and D. Hennessy. 2013. The influence of white clover inclusion in perennial ryegrass swards on milk and herbage production in a high $\mathrm{N}$ fertiliser system. Page 81 in Proc. Agric. Res. Forum, Tullamore, Ireland. Agricultural Research Forum, Tullamore, Ireland. 
Egan, M., M. Lynch, D. Hennessy, A. Pol-van Dasselaar, H. Aarts, A. d. Vliegher, A. Elgersma, D. Reheul, J. Reijneveld, and J. Verloop. 2015. Herbage and milk production from a grass-only sward and grass-white clover swards in an intensive grass-based system. Pages 93-95 in Grassland and Forages in High Output Dairy Farming Systems: Proc. 18th Symp. Eur. Grassl. Fed., Wageningen, the Netherlands. Wageningen Academic Publishers, Wageningen, the Netherlands.

Elgersma, A., S. Tamminga, and G. Ellen. 2006. Modifying milk composition through forage. Anim. Feed Sci. Technol. 131:207-225.

Fellendorf, S., M. G. O'Sullivan, and J. P. Kerry. 2016. Impact of ingredient replacers on the physicochemical properties and sensory quality of reduced salt and fat black puddings. Meat Sci. 113:17-25.

Fernández-Trujillo, J. P., N. Dos-Santos, R. Martínez-Alcaraz, and I. Le Bleis. 2013. Non-destructive assessment of aroma volatiles from a climacteric near-isogenic line of melon obtained by headspace stir-bar sorptive extraction. Foods 2:401-414.

Goodner, K. 2008. Practical retention index models of OV-101, DB-1, DB-5, and DB-Wax for flavor and fragrance compounds. Lebensm. Wiss. Technol. 41:951-958.

Hagen, B. F., J. L. Berdagué, A. L. Holck, H. Næs, and H. Blom. 1996. Bacterial proteinase reduces maturation time of dry fermented sausages. J. Food Sci. 61:1024-1029.

Henneberry, S., M. G. O'Sullivan, K. N. Kilcawley, P. M. Kelly, M. G. Wilkinson, and T. P. Guinee. 2016. Sensory quality of unheated and heated Mozzarella-style cheeses with different fat, salt and calcium levels. Int. J. Dairy Technol. 69:38-50.

Hurtaud, C., L. Delaby, J. Peyraud, J. Durand, J. Emile, C. Huyghe, and G. Lemaire. 2002. Evolution of milk composition and butter properties during the transition between winter-feeding and pasture. Pages 574-575 in Multi-Function Grasslands: Quality Forages, Animal Products and Landscapes. Proc. General Meeting Eur. Grassl. Fed., La Rochelle, France. Organizing Committee of the European Grassland Federation.

Hurtaud, C., L. Delaby, and J.-L. Peyraud. 2007. The nature of preserved forage changes butter organoleptic properties. Lait 87:505519.

Hurtaud, C., and J. Peyraud. 2007. Effects of feeding camelina (seeds or meal) on milk fatty acid composition and butter spreadability. J. Dairy Sci. 90:5134-5145.

International Dairy Federation. 1996. Milk. Determination of fat content (Röse Gottlieb gravimetric method). IDF, Brussels, Belgium.

International Organization for Standardization. 1988. Sensory analysis. General guidance for the design of test rooms. ISO, Geneva, Switzerland.

Keen, A., and R. Wilson. 1992. Effect of breed on colour and flavour. Pages 50-54 in Proc. Milk Fat Flavour Forum, Palmerston North, New Zealand. New Zealand Dairy Research Institute, Palmerston North, New Zealand.

Kelly, M. L., E. S. Kolver, D. E. Bauman, M. E. Van Amburgh, and L. D. Muller. 1998. Effect of intake of pasture on concentrations of conjugated linoleic acid in milk of lactating cows. J. Dairy Sci. $81: 1630-1636$

Koba, K., and T. Yanagita. 2014. Health benefits of conjugated linoleic acid (CLA). Obes. Res. Clin. Pract. 8:e525-e532.

Krause, A. J., R. E. Miracle, T. H. Sanders, L. L. Dean, and M. A. Drake. 2008. The effect of refrigerated and frozen storage on butter flavor and texture. J. Dairy Sci. 91:455-465.

Kulkarni, S., and M. Ramamurthy. 1985. Studies on changes in rheological characteristics of butter stored at different temperature for different periods. Indian J. Dairy Sci. 38:111-114.

Lamarche, B., I. Givens, S. Soedamah-Muthu, R. M. Krauss, M. U. Jakobsen, H. A. Bischoff-Ferrari, A. Pan, and J.-P. Després. 2016. Does milk consumption contribute to cardiometabolic health and overall diet quality? Can. J. Cardiol. 32:1026-1032.

Leffingwell, J. C., and E. Alford. 2011. Volatile constituents of the giant puffball mushroom (Calvatia gigantea). Leffingwell Reports $4: 1-17$.

Lerch, S., K. Shingfield, A. Ferlay, A. Vanhatalo, and Y. Chilliard. 2012. Rapeseed or linseed in grass-based diets: Effects on conju- gated linoleic and conjugated linolenic acid isomers in milk fat from Holstein cows over 2 consecutive lactations. J. Dairy Sci. 95:7269-7287.

Lopez, C., F. Lavigne, P. Lesieur, C. Bourgaux, and M. Ollivon. 2001. Thermal and structural behavior of milk fat. 1. Unstable species of anhydrous milk fat. J. Dairy Sci. 84:756-766.

Mannion, D. T., A. Furey, and K. N. Kilcawley. 2015. Free fatty acids quantification in dairy products. Int. J. Dairy Technol. 69:1-12. http://dx.doi.org/10.1111/1471-0307.12301.

Marsili, R. 2003. Flavours and off-flavours in dairy foods. Pages 1069 1073 in Encyclopedia of Dairy Science. H. Roginski, ed. Academic Press, London, UK.

Mohammed, R., C. Stanton, J. Kennelly, J. Kramer, J. Mee, D. Glimm, M. O'Donovan, and J. Murphy. 2009. Grazing cows are more efficient than zero-grazed and grass silage-fed cows in milk rumenic acid production. J. Dairy Sci. 92:3874-3893.

Moio, L., J. Dekimpe, P. Etievant, and F. Addeo. 1993. Neutral volatile compounds in the raw milks from different species. J. Dairy Res. 60:199-213.

Mortensen, G., G. Bertelsen, B. K. Mortensen, and H. Stapelfeldt. 2004. Light-induced changes in packaged cheeses - A review. Int. Dairy J. 14:85-102.

Mortenson, M. A., Z. M. Vickers, and G. A. Reineccius. 2008. Flavor of whey protein concentrates and isolates. Int. Dairy J. 18:649-657.

Noziere, P., B. Graulet, A. Lucas, B. Martin, P. Grolier, and M. Doreau. 2006. Carotenoids for ruminants: From forages to dairy products. Anim. Feed Sci. Technol. 131:418-450.

O'Callaghan, T. F., D. Hennessy, S. McAuliffe, K. N. Kilcawley, M. O'Donovan, P. Dillon, R. P. Ross, and C. Stanton. 2016. Effect of pasture versus indoor feeding systems on raw milk composition and quality over an entire lactation. J. Dairy Sci. 99:9424-9440. http://dx.doi.org/10.3168/jds.2016-10985.

Peterson, D., and G. Reineccius. 2003. Characterization of the volatile compounds that constitute fresh sweet cream butter aroma. Flavour Fragrance J. 18:215-220.

Poppitt, S. D., G. F. Keogh, T. B. Mulvey, B. H. McArdle, A. K. MacGibbon, and G. J. Cooper. 2002. Lipid-lowering effects of a modified butter-fat: A controlled intervention trial in healthy men. Eur. J. Clin. Nutr. 56:64-71.

Prache, S., A. Priolo, H. Tournadre, R. Jailler, H. Dubroeucq, D. Micol, B. Martin, J. Durand, J. Emile, and C. Huyghe. 2002. Traceability of grass-feeding by quantifying the signature of carotenoid pigments in herbivores meat, milk and cheese. Pages 592-593 in Multi-Function Grasslands: Quality Forages, Animal Products and Landscapes. Proc. 19th General Meeting of the Eur. Grassl. Fed., La Rochelle, France. Organizing Committee of the European Grassland Federation.

Rasmussen, B. M., B. Vessby, M. Uusitupa, L. Berglund, E. Pedersen, G. Riccardi, A. A. Rivellese, L. Tapsell, K. Hermansen, and K. S. Group. 2006. Effects of dietary saturated, monounsaturated, and n-3 fatty acids on blood pressure in healthy subjects. Am. J. Clin. Nutr. 83:221-226.

Rohm, H., M. Strobl, and D. Jaros. 1997. Butter colour affects sensory perception of spreadability. Z. Lebensm. Unters. Forsch. A 205:108-110

Šimat, V., T. Bogdanović, V. Poljak, and S. Petričević. 2015. Changes in fatty acid composition, atherogenic and thrombogenic health lipid indices and lipid stability of bogue (Boops boops Linnaeus, 1758) during storage on ice: Effect of fish farming activities. J. Food Compos. Anal. 40:120-125.

Söllner, K., and P. Schieberle. 2009. Decoding the key aroma compounds of a Hungarian-type salami by molecular sensory science approaches. J. Agric. Food Chem. 57:4319-4327.

Stone, H., R. Bleibaum, and H. A. Thomas. 2012a. Test strategy and design of experiments. Pages 117-157 in Sensory Evaluation Practices. 4th ed. H. Stone, R. N. Bleibaum, and H. A. Thomas, ed. Academic Press, San Diego, CA.

Stone, H., R. N. Bleibaum, and H. A. Thomas. 2012b. Affective testing. Pages 291-325 in Sensory Evaluation Practices. 4th ed. H. Stone, R. N. Bleibaum, and H. A. Thomas, ed. Academic Press, San Diego, CA. 
Stone, H., and J. L. Sidel. 2004. Affective testing. Pages 247-277 in Sensory Evaluation Practices. 3rd ed. H. Stone and J. L. Sidel, ed. Academic Press, San Diego, CA.

Toso, B., G. Procida, and B. Stefanon. 2002. Determination of volatile compounds in cows' milk using headspace GC-MS. J. Dairy Res. 69:569-577.

Ulbricht, T. L., and D. A. Southgate. 1991. Coronary heart disease: Seven dietary factors. Lancet 338:985-992.

van Den Dool, H., and P. D. Kratz. 1963. A generalization of the retention index system including linear temperature programmed gas-liquid partition chromatography. J. Chromatogr. 11:463-471.

Verkerk, G. 2003. Pasture-based dairying: Challenges and rewards for New Zealand producers. Theriogenology 59:553-561.
Villeneuve, M.-P., Y. Lebeuf, R. Gervais, G. Tremblay, J. Vuillemard, J. Fortin, and P. Chouinard. 2013. Milk volatile organic compounds and fatty acid profile in cows fed timothy as hay, pasture, or silage. J. Dairy Sci. 96:7181-7194.

Wright, A., M. Scanlon, R. Hartel, and A. Marangoni. 2001. Rheological properties of milkfat and butter. J. Food Sci. 66:1056-1073.

Yarlagadda, A. B., M. G. Wilkinson, S. P. Ryan, I. A. Doolan, M. G. O'sullivan, and K. N. Kilcawley. 2014. Utilisation of a cell-free extract of lactic acid bacteria entrapped in yeast to enhance flavour development in Cheddar cheese. Int. J. Dairy Technol. 67:21-30. 